\title{
DOE/OR/00033--138
}

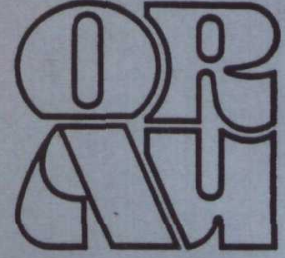

Prepared by Oak Ridge Associated Universities

Prepared for Office of Nuclear Safety U... Denartment of Energy

REVIEW OF OVERALL SAFETY MANUAL FOR SPACE NUCLEAR SYSTEMS

\section{An Evaluation of a Nuclear Safety Analysis Methodology for Plutonium-Fueled Space Nuclear Systems}

\author{
James Coleman \\ Sigma Associates \\ Herbert Inhaber
}

Oak Ridge National Laboratory

DO NOT MICROFILM COVER

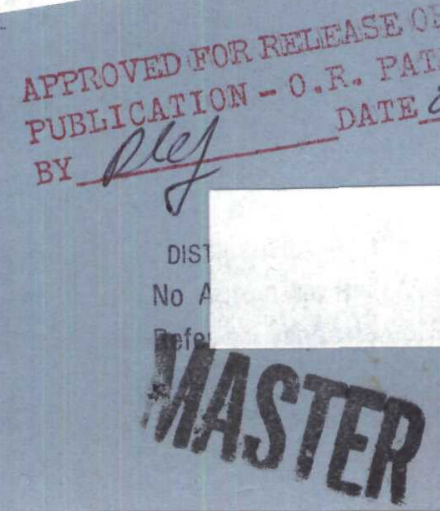




\section{DISCLAIMER}

This report was prepared as an account of work sponsored by an agency of the United States Government. Neither the United States Government nor any agency Thereof, nor any of their employees, makes any warranty, express or implied, or assumes any legal liability or responsibility for the accuracy, completeness, or usefulness of any information, apparatus, product, or process disclosed, or represents that its use would not infringe privately owned rights. Reference herein to any specific commercial product, process, or service by trade name, trademark, manufacturer, or otherwise does not necessarily constitute or imply its endorsement, recommendation, or favoring by the United States Government or any agency thereof. The views and opinions of authors expressed herein do not necessarily state or reflect those of the United States Government or any agency thereof. 


\section{DISCLAIMER}

Portions of this document may be illegible in electronic image products. Images are produced from the best available original document. 


\section{DISCLAIMER}

This report was prepared as an account of work sponsored by an agency of the United States Government. Neither the United States Government nor any agency thereof, nor any of their employees, makes any warranty, express or implied, or assumes any legal liability or responsibility for the accuracy, completeness, or usefulness of any information, apparatus, product, or process disclosed, or represents that its use would not infringe privately owned rights. Reference herein to any specific commercial product, process, or service by trade name, trademark, manufacturer, or otherwise does not necessarily constitute or imply its endorsement, recommendation, or favoring by the United States Government or any agency thereof. The views and opinions of authors expressed herein do not necessarily state or reflect those of the United States Government or any agency thereof.

The mission of the Manpower Education, Research, and Training Division, formed in 1977 , is to enhance the knowledge and abilities of the professional and skilled work force involved in national energy, environmental, and health-related activities. The division is organized into five program areas that examine human resource issues, evaluate manpower requirements and training needs, assist in establishing manpower training programs, and provide opportunities for professional education and industrial craft training. The division's programs include the Assessment and Field Support Program, the Labor and Policy Studies Program, Professional Training Programs, the Training and Technology Program, and University Programs.

\section{NOTICES}

The opinions expressed herein do not necessarily reflect the opinions of the sponsoring institutions of Oak Ridge Associated Universities.

This report was prepared as an account of work sponsored by an agency of the United States Government. Neither the United States Government nor any agency thereof, nor any of their employees, makes any warranty, express or implied, nor assumes any legal liability or responsibility for any third party's use or the results of such use of any information, apparatus, product or process disclosed in this report, nor represents that its use by such third party would not infringe privately owned rights. 
DE90 010925

\title{
REVIEW OF OVERALL SAFETY MANUAL FOR SPACE NUCLEAR SYSTEMS
}

\section{An Evaluation of a Nuclear Safety Analysis Methodology for Plutonium-Fueled Space Nuclear Systems}

\author{
James Coleman \\ Sigma Associates
}

and

Herbert Inhaber

Oak Ridge National Laboratory

February 1984

NOTICE

This report contains information of a preliminary nature and was prepared primarily for internal use at the originating installation. It is subject to revision or correction and therefore does not represent a final report. It is passed to the recipient in conflence and should not be abstracted or further disclosed confldence and should not be abstracted or further disclosed Technical Information Center, Oak Ridge, TN 37830.

Prepared for

U.S. Department of Energy

Assistant Secretary, Environmental Protection, Safety, and Emergency Preparedness Office of Nuclear Safety

Prepared by

Assessment and Field Support Programs Manpower Education, Research, and Training Division

Oak Ridge Associated Universities P.O. Box 117

Oak Ridge, Tennessee 37831-0117

This report was prepared under contract number DE-AC05-760R00033 between the U.S. Department of Energy and Oak Ridge Associated Universities. 
Page

I. INTRODUCT ION . . . . . . . . . . . . . . . . . . 1

11. OVERALL CONCLUSIONS AND RECOMMENDATIONS .......... 4

111. REVIEW OF AND RECOMMENDATIONS ON RISK 11 MODEL (VOLUME 2) • 11

IV. REV IEW OF AND RECOMMENDATIONS ON RISK $\mid \|$ MODEL (VOLUME 4) • 16

V. REVIEW OF AND RECOMMENDATIONS ON DATA BASE (VOLUME 3 ) . • 21

VI. APPENDICES

1. WORK STATEMENT OF JULY 13, 1983 . . . . . . . . . 24

2. DETAILED COMMENTS ON VOLUME $2 \ldots \ldots 25$

3. DETAILED COMMENTS ON VOLUME $3 \ldots . . . . . . . . .48$

4. DETAILED COMMENTS ON VOLUME 4 ............. 55 


\section{INTRODUCT ION}

As part of its duties in connection with space missions involving nuclear power sources, the Office of Nuclear Safety (ONS) of the Office of Assistant Secretary for Environmental Protection, Safety, and Emergency Preparedness has been assigned the task of reviewing the lverall Safety Manual (OSM) (memo from B. J. Rock to J. R. Maher, December 1, 1982). The OSM, dated July 1981 and in four volumes, was prepared by NUS Corporation, Rockville, Maryland, for the U.S. Department of Energy.

The OSM provides many of the technical models and much of the data which are used by (1) space launch contractors in safety analysis reports and (2) the broader Interagency Nuclear Safety Revlew Panel (INSRP) safety evaluation reports. If the interaction between the OSM, contractors, and INSRP is to work effectively, the OSM must be accurate, comprehensive, understandable, and usable.

The authors have been engaged to assist ONS in its review of the OSM. A copy of the work statement for our effort is attached as Appendix 1 . In this effort, we have tried to put ourselves in the position of potential users unfamiliar with the manual, but with more technical background than casual readers. If there are parts of the manual which we have misunderstood or falled to understand, we feel that similar problems will occur to many users.

The present task is only part of a wider effort. Technical panels, such as those on oceanography and meteorology, have been set up to review specific areas of the OSM. However, our effort is the only study of the total document.

As noted in the work statement, our task was to review the OSM in a broad way without concentrating on the details. In the course of our review we made specific comments in developing our generalizations. These specific comments are included as appendices to this report. We belleve they will be useful for any revisions of the OSM and are in no way meant to intrude on the work of the technical panels.

Consistent with the work statement, we emphasized reviewing the risk models. Our effort included an evaluation of the overall risk analysis methodology presented in the manual and the technical rationale supporting the methodol ogy.

In addition, we have al so evaluated other aspects of the OSM, such as its usability, data base, and so on. The review of these other aspects was 
required in order to provide a comprehensive picture of the value of the document.

The OSM is composed of four large volumes, with hundreds of pages and scores of figures, graphs, tables, computer printouts and other materlals. As a result, organizing our comments so that they will be useful to both those familiar and those less familiar with the OSM was not an easy task. Because some readers will be interested in our overall conclusions and other readers will be concerned with specific I ine-by-line comments, we have divided this report into two broad segments, corresponding roughly to this division of interest.

The next four chapters contain our general comments, conclusions, and recommendations. Chapter 11 is our overall conclusions and recommendations. Chapters III, IV, and $V$ are more specific conclusions and recommendations for Volumes 2, 4, and 3, respectively. The numerical order of the volumes is not that of the chapters because Volume 3, the data base for the risk models, is of necessity a subsidiary volume. Appendices 2 through 4 contain detalled comments on Volumes 2 through 4, respectively, of the OSM. Volume 1, while providing some background material, is primarily a guide to the other volumes rather than providing a description of how to use them. While it was reviewed as a part of our effort, we have not offered specific comments here. Chapter 11 includes in part our consideration of that volume.

Our comments and recommendations are not necessarlly in order of importance, because we are dealing with many levels of criticism. The degree of importance assigned to each comment will ultimately depend on the use to which this document is put.

Whenever possible, we have tried to link our recommendations to the preceding discussion and conclusions by a clear chain of reasoning. This will al low readers to judge for themselves the validity of our comments. For graphical clarity, each set of comments and recommendations is separated by a line.

Some of our broad conclusions noted in Chapter II, and applicable to al 1 four volumes, are of course applicable to specific volumes. To avoid redundancy when our conclusions on specific volumes (Chapters III through $V$ ) overlapped those on the OSM as a whole (Chapter 11), we have abbreviated the former comments and referred to Chapter 11 . 
In the nature of a review, the ratio of unfavorable to favorable comments is often high. This is true here. However, there are many parts of the OSM which were diligently done and clearly reflect a great amount of good work. These facts should be kept in mind through all the following pages.

It is our belief that if the OSM were revised along the I ines we suggest, and if pursued in conjunction with implementation of the recommendations of the other technology experts reviewing the OSM, it would strengthen the effectiveness of the Manual for a broad spectrum of users, ranging from space launch contractors to decisionmakers in federal agencies. In addition, with the proposed revisions, it could serve as a scientific landmark, similar to WASH-1400 for nuclear power reactors -- an example of a detailed risk analysis of an enormously complicated technological endeavor. We offer these comments in a constructive spirit in the hope that the OSM will eventually become the landmark it deserves to be. 


\section{Qverall Approach and Users}

The idea of applying risk analyses to space nuclear systems is a significant and important concept and could be a key tool in the evaluation of both mission and systems. The OSM has performed a great service, in assembling a vast array of data and theory bearing on the subject. The preparers of this document deserve congratulations.

For this document to be broadly useful, the description of the concept must be readable and understandable and its method of presentation clear. We have, in many cases, not found these aspects in the OSM.

The goal of the OSM approach, as with any risk analysis model, is to produce information relating to the probability that a population will be exposed to some specific stress. In general, this starts with calculating the probability that a given number of individuals will recelve a radiation dose greater than any specific value.

The next step is to relate the potential radiation exposure to health effects through a dose-response model. Through this mechanism, one can use the dose distribution data to estimate the probability distribution of deleterious health effects associated with environmental releases as well as the total number of effects. This presumably is the purpose of the OSM analysis.

Yet nowhere in the four volumes is the reader provided with a straightforward description of the OSM approach and how it is intended to be used. The OSM is simply offered as "standardized guidance" for risk and environmental analyses. This fallure comes about because the overall analytical approach is never clearly described. A start is made in Chapter 5 (p. 5-6) of Volume 1 and Chapter 1 ( $p .1-1$ ) of Volume 4 by outlining a five step process, but unfortunately, there is no follow-up. The steps are treated separately in the body of the document, but no effort is made to show how the five steps fit together. A users' guide, such as the Instruction Kit described at the beginning of Volume 4 , would be helpful in this context.

The OSM concept can serve as a useful and effective guide for consistent and comparable safety analyses for Space Nuclear Systems. However, because of its I imitations as identifled in this review, the OSM is of only partial practical use to audiences other than its developers. 
Recommendation 1:

The present OSM should be revised so that groups other than its developers can employ it. It should be usable by those with suitable technical background but not completely familiar with risk analysis. Specifically, the revision should include a clear description of the overall approach to risk analysis and a step-by-step users' guide.

\section{Editorial Adequacy}

In many places, we get the impression that the documents have been patched together from a variety of sources, some of which may have been prepared for other purposes. There is often inadequate continuity from one section or volume to the next. A wlde variation in the clarity of explanation from section to section magnifies this patchwork effect. Some portions are quite clear, while others merely dump the information in the reader's lap. Typographical errors appear frequently and are sometimes propagated from chapter to chapter or volume to volume. Some are small, but others are significant. As an example of the patchwork effect, Appendix A of Volume 4, Risk III, appears to be edited from a more detailed document. See more detalled conclusions and recommendations in Chapter IV below.

Unnecessary variations in nomenclature are common. For example, atmospheric stability catagories are referred to as both 1 through 7 and $A$ through $G$ in both Volume 2 and Volume 4. Further, typographical errors in the symbols for Koppen meteorologlcal categories are carried over from Appendix $D$ of Volume 2 to Chapter 2 in the same volume, making interpretation additionally difficult.

Finally, the format of tables and graphs are not consistent from volume to volume or in many cases from chapter to chapter. Definitions used in parameters, graphics, and equations are not consistent. For example: "Ground Plane Concentration" in Appendix A of Volume 4; "Integrated Ground Concentration" and "Deposition" in Chapter 2 of Volume 2; and "Deposition Density" in Appendix D of Volume 2 all refer to the same physical quantity. In summary, the OSM clearly has been developed by a number of different authors over an extended period of time. It thus contains both inconsistent writing, typographical errors, and many other problems. Particularly lacking is a consistent format for tables and graphs as well as consistency in definitions of physical parameters. Parts of the OSM give the clear indication of a cut and paste effort. 


\section{Recommendation 2:}

The OSM should be rewritten in a consistent manner with suitable editorial input of a nontechnical nature. This should include a defined format for tables and graphs as well as the same terms for equivalent physical quantities. We definitely recomend against a cut and paste effort--we consider a complete rewriting necessary.

\section{Risk $\|$ and Risk $\|$}

The OSM provides two approaches for generating and presenting risk analysis data. They are defined in part as:

RISK LI (Volume 2): Estimates of radiation doses to the general population following a postulated release of activity on a time scale of about one year.

RISK U (Volume 4): This provides a method of extending the analysis to time scales on the order of hundreds or thousands of years.

Although Risk 111 extends the analysis to health effects, the only substantial conceptual difference between these two models appears to be the time frame of analysis. Handling of dose-effect threshholds may also be different in the two models, although this point is not clear. It is stated that the Risk 111 model is both more complex in some ways and more simplified in others than Risk 11 and that the Risk 111 model addresses more pathways over longer periods of time. Yet nelther the additional pathways nor their importance in relation to Risk II pathways are identified or discussed.

There does not appear to be either a conceptual nor practical reason for continued use of the dual analysis other than that they are both now available.

\section{Recommendation 3:}

The OSM should incorporate the broad concepts of RIsk II and Risk Ill into a single risk model.

\section{Different Submodels}

There are a number of places within the OSM where slightly different submodels are used to solve the same problem. A prime example is the case of atmospheric dispersion for which at least three treatments are presented. For example, a comprehensive dispersion model is provided in Appendix $D$ of Volume 2 with great detail, including modifled stabllity parameters and a treatment of resuspension. However, in Chapter 2 of the same volume a slightly different 
adaptation is used, one that includes reflection for both the ground boundary and an inversion cap but does not include the modifications identified above. A third atmospheric dispersion model is used in Risk 111 , although this model is not described but only identified as an existing computer code.

Another example of duplicate treatment is the food chain model, which again is different in Risk 11 and Risk III. In this instance, Risk 11 utilizes the model described in detall in Appendix $F$ of Volume 2, but Risk 111 introduces a new approach not previously described.

Finally, a modification to the inhalation model is introduced in Section 8 of Appendix A of Volume 4, Risk 111. This model differs somewhat from the model included in Volume 2. This multiplicity of models serving the same apparent purpose is a source of confusion for any user of the OSM. Such differences do not appear necessary or reasonable.

Recommendation 4:

The duplication of submodels should be el iminated, or the purpose of presenting different modeling approaches to the same problem should be clarified.

\section{Source Term}

As part of our work scope, we were directed to evaluate the source term methodology as well as its uncertainties. Although some source term probabilistic mathematics are given in Chapter 2.1 of Volume 2, unfortunately little discussion is presented in the OSM on its physical parameters. A specific analysis on pages 2.1-8 and 2.1-9 recognizes that information may be lacking and simply states that assumptions must be made. The only assumption given is that 10 percent of the total fuel might be released, followed by a vague reference to conservatism. This simple presentation is inadequate.

In Risk III (Volume 4) even less attention is paid to this question. On page 1-1, while pointing out that the definitions of source term must include particle size, released mass, isotopic composition, etc., the only guidance provided is that the initial source must be defined based on system design and mission profile. This is also inadequate. 


\section{Recommendation 5:}

The parameters and analysis model approprlate for source term definition should be supplied. Some explicit consideration of uncertaintles should also be given.

\section{Updated Models and Data}

In addition to inconsistency in modeling, several highly dated modeling approaches and data are utllized in OSM. Of specific concern are the model approach used for high altitude vapor debris and the model used for high altitude release of larger particulates.

In the former, the prediction is based on the simple assumption that the returning high altitude vapor debris from space systems could be characterized by the observed latitudinal distribution of weapons test strontium-90 deposition through the end of the year 1965. Two questions occur: Is the comparison with strontium-90 from weapons debris still the only or most reasonable assumption? Are there no more recent data that would be helpful?

The deposition patterns for high altitude releases of larger particles were generated by a modified version of the "Model B" (Reference 21, Volume 4, and Reference 2.5-6, Volume 2) computer code. This computer code was developed for computer capabilities at least 20 years old and may not even be avallable. The modification by NUS has, as far as we can determine, never been documented.

In addition, much of the data base, particularly the population data, is significantly outdated. All of this tends to give the picture of an OSM that is approximately 10 to 15 years old, which detracts from its crediblitity.

\section{Recommendation 6:}

The dated portions of both model ing and data components included in the OSM should be updated, or specific discussion on their continued applicabllity should be provided. The portions updated should be identified.

\section{Uncertaintles and Sensitivity}

Throughout the entire OSM, there is no real discussion of the uncertainties in the individual models, the overall risk analyses, or how these uncertainties might reflect on a decisionmaker's judgment. In some cases, as with source terms noted in Chapter 2 of Volume 2, the uncertainty may be an order of magnitude. In other cases, for example, the worldwide distribution of 
stratospheric vapor debris, one might conclude from Appendix D of Volume 2 that the uncertainty is roughly a factor of two. One might assume that the uncertainty resulting from population data might be less than a factor of two. Uncertainty information is very important to any understanding and interpretation of the final risk estimates, but unfortunately there is no effort to either identify uncertainties with in the various models, the uncertainties in the data base, or the effect on the final risk estimate.

Both the uncertainty of the input data and model parameters as well as the sensitivity of the final risk estimate to these inputs is important. For example, an environmental quantity may be uncertain to within a factor of ten, but if it accounts for only one-thousandth of a percent of the overall risk, its uncertainty will not be significant.

A clear exposition of uncertainty within the models and the sensitivity of the total risk estimate to these uncertainties is important for two reasons: without some understanding of the uncertainty inherent in the analysis it is impossible to rationally evaluate the overall risk, and a clear exposition of uncertainty within a sensitivity analysis will be the most effective way of identifying additional data and modeling needs.

\section{Recommendation 7:}

A comprehensive effort should be undertaken to estimate and document the uncertainty of the individual models and the sensitivity of overall risk estimates to these uncertainties.

\section{Experimental Data}

In some areas, applicable experimental data have not been used to the greatest advantage. A particular case of interest is the impact test results presented in Appendix A4 of Volume 3. In that appendix, the results of a great many impact tests are reported (reporting particle size distributions and impact velocities along with other pertinent data). These data would seem of key importance to any estimation of source terms but are apparently never interpreted.

For example, on page 2.1-8 of Volume 2 where these data are referenced, it is simply stated that ". . It was assumed that fracturing is proportional to impact kinetic energy," and thus on page 2.1-9 the fractured particulate fractions are scaled to the square of the impact velocity. The results of the 
impact tests should support something stronger than an assumption, unless the data are stated to be inappropriate. In any event, an analysis of the data should be presented either in Volume 2 or Volume 3.

Recommendation 8:

When approprlate test data are avallable, these should be used to support or modify assumptions. This is of particular importance in clarifying the uncertainty in source term estimates.

\section{Application to Reactor Systems}

Both Volume 1 and Volume 2 expressly indicate that the OSM is addressed to plutonlum-fueled systems. However in Volume 4 there is an attempt to introduce some consideration of reactor systems through source terms and pathway analyses. There is increasing interest in space reactor systems and the extension of the OSM to such systems could prove an extremely worthwhile effort. Before such an effort is undertaken however, it is important that data and analysis needs necessary to extend the OSM to reactor systems be identified.

Recommendation 9:

Recognizing that space reactor systens are becoming of increased Importance, an effort should be undertaken to Identify the data and modeling needs necessary to extend the OSM approach to such reactor systems.

\section{Index}

Finally, it must be recognized that there are masses of data, models, and concepts within the OSM. It is almost impossible to Identify the location of specific pieces of information without some form of comprehensive index. Such an index could also help to note and reduce areas of duplication mentioned above.

Recommendation 10:

A comprehensive Index of the OSM should be prepared. 
111. REV IEW OF AND RECOMMENDATIONS ON RISK II MODEL (VOLUME 2)

\section{Updating Material}

The date of this volume is 1975. From this and other more substantive reasons, it is clear that we are dealing with a compilation of material that is at least ten years old.

\section{Recommendation 1:}

As noted in Chapter II, the OSM should be updated and the portions updated should be clearly identified. We are not prepared to state which sections should be updated, but a sensitivity analysis, such as recommended In Chapter II, should be helpful.

\section{Risk $\|$ and Probability}

The purpose of this volume is to describe a model called Risk 11 and illustrate its use. However, nothing is mentioned about Risk I, if it ever existed, and how Risk $11 \mathrm{might}$ be different. In a later volume, a model entitled Risk 111 is discussed, but this model is barely mentioned in the present volume. The overall impression is that of discontinuity and lack of explanation.

Few of the equations and assumptions are combined in a logical and straightforward manner. The reader seems to be expected to take final equations for various subchapters and combine them in some unspecified manner to produce a final estimate of risk. A prime example of this is in Chapter 2.1, which has a large number of equations but no overall picture of their interrelationships.

A key question is avolded: How can the probability of different types of accidents be calculated? Until this is answered, an adequate risk assessment has not been done. It seems strange that the calculations leading up to previous launches have not been employed here. While a full discussion of this question is probably not possible due to space limitations, some indication of possible ranges should be given. 
Recommendation 2:

As noted in Chapter II, the two risk models should be incorporated into one. No equation should be included without a clear explanation of how it fits into overall risk calculations. In order to perform a full risk assessment, some indication should be given, at least theoretically, of the probabllity of different fallure types. Some previous launch data would be helpful.

\section{Uncertainties and Precision}

There are a number of questions related to precision, uncertainty, and sensitivity that arise in reviewing this volume. There is hardly any mention of such concerns, much less any estimation of the uncertainty attached to various parameters or calculations presented. This may lead the reader to bel ieve that these values are known to a high degree of accuracy, which is not the case.

There is almost a continuous problem in fitting precision together. For example, some calculations are extremely precise, to five or six significant figures, whereas other assumptions are probably valid only to within an order of magnitude. There is little point in great precision in one calculation if it is combined with others with much less precision.

There is little if any indication that the physical data and assumptions have been experimentally verified in any way. Much experimental work has been done on the physical quantities used, but little evidence of this appears. More emphasis should be placed on models and constants that have been verifled and how the verification was done.

The relationship between conservatism and realism is a key one in risk calculations. Unfortunately, rarely, if ever, is it made clear if the authors are using conservative or realistic assumptions or whether the question was even consldered. Use of conservative assumptions will, in general, lead to overestimates of risk, but these overestimates may be acceptable in some instances. For example, at one point it is assumed that eight glasses of water are consumed by the average person. Is this conservative, realistic, or somewhere in between? Many of these problems could be allevlated with the use of the uncertainty/sensitivity analysis recommended in Chapter 11. 
Recommendation 3:

Whenever possible, estimated uncertainties should accompany

values. If possible these uncertainties should be combined to estimate the overall uncertainty of the risk analysis.

\section{Using the Models}

There are a number of questions relating to combining models, their sources, and a user's manual. For example, on page 2.0-1, it is stated that readers can perform manual risk analyses if desired. However, no indication is given of how this can be done. In our opinion, the provision of manual procedures whereby users could test the data and assumptions would be most valuable.

The elaborate models in Chapter 2 are presented as if they are the only way to proceed. Many equations seem to come out of the blue with little or no explanation. No indication is given if simpler models have been considered. simpler models might be briefly mentioned as well as any accuracy that is lost by using them.

Appendix $B$, the user's manual for the Risk 11 code, is so general as to be almost useless. It apparently is the vestige of a more comprehensive manual which may have been of some use. It is not helpful to the overall understanding of Risk 11 .

\section{Recommendation 4:}

Means should be provided whereby users can manually check many, if not all, calculations. As noted in Chapter II, a step-by-step gulde to using the OSM, with examples, and both workable and accurate, should be prepared. More discussion of models is needed.

\section{Editing}

A number of problems occur because of inadequate technical editing. Lack of consistency bedevils the reader in many places. We cannot list all the cases although some are noted in the appendices. An example occurs on page 2.5-18, where the size of the latitude bands differ from those in previous sections, without any explanation.

A number of definitions are less than clear. An example occurs on page 2.1-3 where the physical status corresponding to release is not defined. 
The reader is confronted with a huge mass of numbers in many tables, often with little indication of what are the most significant values. In addition, most tables and graphs are either not explained or poorly explained in the text, making them less than useful. Captions are necessary for clarity.

The references are sometimes inadequate, with page numbers, publishers, places of publication, report numbers, and other bibliographic data missing. In particular, not specifying page numbers for one source of data in a large document seems unreasonable.

Finally, Appendix A, the list of symbols, contains about 200 entrles--and as noted above, some of these symbols are used in a confusing manner. The sheer volume of these symbols is an indication of the document's complexity. It is by no means apparent that all this complexity is necessary.

\section{Recommendation 5:}

Technical editing as recommended in Chapter II should be undertaken. Consistent graph captions and definitions should be used. Efforts should be made to Integrate all tables and graphs into the text by clear explanations, and references should be brought up to blbllographic standards.

\section{Lntegrating Appendlces}

Appendix $C$ is obviously written by meteorologists for other meteorologists. While these data are likely essential for the risk calculations, little or no effort has been made to integrate this information with the rest of the text.

\section{Recommendation 6: \\ Appendices should be clearly related to the main text by approprlate references between the two sources.}

\section{Computer Codes}

As noted in other chapters, there is extensive rel iance on computer codes which may be inaccessible to many readers (see, for example, page 2.5-8). Readers are therefore unable to evaluate how val id or useful models or data bases are. 
Recommendation 7:

At least the main assumptions behind the computer codes cited should be IIsted, if not the codes themselves. Readers should be able to reconstruct the calculations on their own. Actual codes should be avail able to users. 


\section{Risk U Overall}

Appendix $A$ of Volume 4 describing Risk 111 is difficult to follow, appears fragmented, and leaves the reader somewhat at a loss as to how to apply the concepts and information presented.

Risk 111 appears to be only a concept and not a working model. In fact, the discussion presented offers contradictory statements related to a "two stage model development plan." On page 1-5 of Appendix A, two such opposite statements are made:

The Risk 111 model as described in this report actually represents the first stage of a two stage model development plan.

The Risk 111 model reflected by stage two of the development plan is fully described in Reference 1 and Chapter 2. . . (emphasis added)

Thus it is unclear what is really being presented. We assume that Risk III exists only as a broad concept in Section 2 of this Appendix.

It is stated in Section 1 that it is the intent of Risk 111 to address the long-term risk due to radioactivity released into the environment. The time scale of interest is stated to be on the order of thousands of years. Further, it is asserted that many of the environmental pathways neglected in the Risk 11 model must now be considered because of the time scale of the model. However, none are specified. The conceptual structure of Risk 111 and the associated extension of the time frame of analysis is important. However, we question if this is appropriate without some detalled presentation of the significance of long-term exposure and specific pathways.

On page 2-8 a discussion of pathways in terms of primary and secondary importance is presented. Unfortunately no calculations are shown to illustrate the significance of individual pathways. We are left with questions: What pathways must be considered? What parameters are to be used? How does the time frame of reference bear on the relative significance of various pathways?

Risk 111 appears to be only a conceptual model and not an actual working model. It would then appear most reasonable to identify those new pathways and parameters that will have significance in the overall analysis, before going onto further development of Risk III. 
Recommendation 1:

Before continuing with more detalled development of Risk III, a sensitivity/uncertainty analysis should be undertaken in order to determine whlch pathways, parameters, and/or data are of most significance, considering cost of data acquisition.

\section{Consistency of Models}

Much of the developmental work in Risk 111 is very similar to that carried out for Risk II In Volume 2. Included are atmospheric transport, food chain transport, aquatic transport, and human exposure. Similar environmental transport pathways are included in Risk II. Yet different models are used. There appears to be no real reason for the difference in treatment. The time frame of reference certainly does not justify the difference in these basic models. The OSM suffers from this apparent needless duality of approach.

\section{Recommendation 2:}

As noted In Chapter II, consideration should be given to using a single overall risk model. Recommendation 1 above can provide the first step.

\section{Editorial Adequacy}

It is apparent that Appendix A was written for some other purpose and then edited to become part of the OSM. The text references itself several times (for example on pages 5-1 and 5-6) and refers to a nonexistent Appendix (page 2-4). It is obvious that this Appendix must be rewritten if it is to serve as a generally useful document.

\section{Recommendation 3:}

If RIsk III is kept as a separate risk model within the OSM, it must be rewritten specifically for this manual.

\section{Model ing Legic}

Section 5 of Appendix A needs a great deal of work. Specific comments are provided in Appendix 4 of this report. One might start by redrawing Figure 5-5 on page 5-10 to provide a better illustration of the mathematics that fol low. A figure similar to that shown on page 2-3 would be approprlate. Simple figures would al low both the transition matrix for the Markov chain and the 
differential equations for the deterministic analysis to be written. Solutions can then be presented.

A simple presentation such as this would IIluminate the data and parameters needed while not obscuring the problem with a detalled presentation of the mathematical mechanics. The solutions of the differential equations, while somewhat tedious, are quite straightforward. What is much more important are the values to be assigned to transition probabilities and weighting factors (such as deposition velocities, weathering halt-times, resuspension factors, and so on) in order to arrive at the final result.

We have a specific concern about the logic that starts on page 5-11. The assumption is made that airborne concentration as a function of altitude is related to alr density. This is an attempt to define ground level atmospheric concentration. This assumption confuses the question of how ground level concentration relates to ground deposition and produces an inconsistency in the approach to the problem. Relating air concentration to air density defines by implication a deposition velocity through the relationship

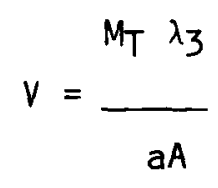

Using the values for the above parameters taken from the text yields a deposition velocity of $4.5 \times 10^{-2}$ meter/second. However, the half-life for the tropospheric reservoir implies a mean residence time which also defines a deposition velocity. Using the height of 10,000 meters and the mean residence time of 14.4 days yields an apparent deposition velocity of about $8 \times 10^{-3}$ meter/second-- thus the inconsistency. This is compounded when later on pages 5-34 and 5-42 a deposition velocity of 0.01 meter/second is actually assumed for further calculations. We thus have three different deposition velocities. This inconsistency should be removed or explained.

\section{Recommendation 4:}

The inconsistencles in section 5 of Appendix A must be clarified or explained if the model is to be useful. 


\section{Qutput of Calculations}

Section 3.5 of this Appendix Implies that mission risk should be reduced to a single point risk estimate. This unfortunately is not clarified later. There may be some value in expressing mission risk as a point estimate, but it can only be generated when all of the intermediate risk information is avallable. It appears that the TDOS model in Appendix B is capable of generating the intermediate dose distribution. However, this is not made clear in the description of Risk III. In fact, nowhere within this volume is there a description of the type of information that is desired from the risk analysis or that which can be generated from Risk 111 .

\section{Recommendation 5:}

A clear description of the information necessary for a risk analysis and the output which can be generated from Risk III should be provided so that the user can formulate a clear picture of what information may be needed and how it may be obtained.

\section{Reducing Risk}

Finally, there is essentially no consideration given to mitigating steps which can or have been taken to reduce risk. For example, the experience recovering space nuclear systems such as Operation Morning Light in Canada and the recovery of the SNAP-19B2 following the abort of the NIMBUS-B1 as well as the clean up near Palomares in Spain are not considered. This is of particular concern with Risk 1/1, which implies that the consequences of an abort are committed risks for hundreds to thousands of years.

In general, the idea of dose commitment in the past has been applied to "normal activities" that one is committed to--not abnormal situations that can be avolded or mitigated by better design (whether hardware, mission, or contamination recovery). Thus the application of the concept of dose commitment, particularly one that may reduce the entire mission to a single point estimate of risk, denies the fact that some radiological consequences of abort can be avolded. 
Recommendation 6:

If the long-term Risk III model is further developed, specific steps must be taken to consider risk mitigation, such as clean up or recovery of fuel. Long-term pathways that may in fact be avolded should not, through solely mathematical calculations, become significant concerns. 


\section{REV IEW OF AND RECOMMENDATIONS ON DATA BASE (VOLUME 3)}

\section{Updating Data}

The first page of this volume is dated January 1975, leading the reader to bel leve that at least some of the data are out of date. It is clear that some of the data, such as that on population in Chapter 2, are obsolete. The substantial population underestimate $(3.7$ billion versus 4.7 billion at present) is immedlately obvious, and the lack of attention to this fact diminishes the document's credibility. Unfortunately, the uncertainty introduced by this underestimate is not discussed.

Other data, such as the meteorological data in Appendix 2.2, appear more current, but again the effect of uncertainties is not discussed. Also, many of the data bases provide no indication of the sources, dates, variability, or limitations.

From time to time, as on page 4.1-1, it is implied that material will be updated in the future. It is our bellef that no promises should be made about further changes in the OSM unless resources are available and a formal plan is developed to fulfill these promises.

The data bases should be updated. However, it is not possible to specify which data bases are most in need of this work, since this is a function of the sensltivity of the overall risk analysis to data variations and the cost of information acquisition. However, if the sensitivity/uncertainty analysis recommended in Chapter 11 of this report were carried out, priorities for updating could be developed.

\section{Recommendation 1:}

An effort should be made to determine which data sets can and should be updated. All data sets should be fully documented with some discussion of Iimitations.

\section{Editorial Adequacy}

The brevity of Chapter 1 of this volume (one paragraph of 11 IInes) is indicative of the lack of integration of the data into a coordinated package. The data are simply thrown together in disconnected chapters with no attempt to relate one data set to the next. Material from one chapter is sometimes repeated in another often without detalled explanation. The volume suffers severely from a lack of technical editing. The chapters and subchapters differ 
strongly in their degree of explanation, with some being clear and others being mere collections of numbers.

Unnecessary typographical variations occur often. For example, the symbols for the Koppen meteorological classifications are different in Tables 2.6-1, 2.6-2, and 2.6-3 of this volume, and all are different from those in Table 2.3-2 in Vol ume 2.

Many data points are carried to far more significant figures than is necessary or appropriate. For example, populations are given to the nearest person, where in reality population may not be known that exactly.

The notations used in some equations is non-uniform in that some symbols are used interchangeably. For example, within a few pages (Chapters 2.1 and 2.2) the symbol $R$ is used for the rate of population increase and the radius of the earth. In the latter case, it is not even defined. Terminology seems to vary from one section to another: vertical distribution in one section means the same as elevation in another.

Overall, one gets the impression that separate chapters were prepared by different authors and that no consistent technical editing was provided.

Recommendation 2:

The volume should be reviewed by a competent technical editor and Chapter 1 should be significantiy expanded to place what follows in context. In particular, it would be helpful to show when and how specific data are used in other volumes of the OSM and the degrees of uncertainty.

\section{Combining Data}

Some data sets are combinations of other sets, but how and why this combination was done is often not clear. An example is shown on page 2.2-1 where population data from different sources are combined in an unknown manner.

There is also non-uniformity in the spatial dimensions used, with some sections assuming 720 cells and others using cells of different dimensions (for example Table 2.4-2).

\section{Recommendation 3:}

The geographic format should be made uniform and consistent. Whenever data sets are combined, the purpose behind this and the mechanics by which it is done should be expressed or be transparent. 
The relationship of much of the data to risk calculations is often obscure at best. A prime example is Chapter 3, which reads more like an environmental impact statement than a data base. Its relationship to calculations in other volumes is unclear. Parts read as if they had been transcribed from other descriptive publications.

Parts of this volume seem too lengthy. The section on meteorology in Chapter 3 is an example.

\section{Recommendation 4:}

Volume 3 should be revised to minimize the presentation of materlal which is not essential to risk calculations. The relationship of all data bases to final risk calculations should be made evident.

\section{Computer Programs}

As is often the case in each of the volumes considered, reference is made to computer programs which are inaccessible to most readers. An example in this volume is page $2.6-1$.

\section{Recommendation 5:}

Since IIsting complete computer codes will probably take considerable space, at a minimum the major assumptions behind codes used in the OSM should be mentioned as well as how readers can access the codes. 
In its role of participating in the reviews of the safety analyses required for launch approval of U.S. space missions involving nuclear power sources, the Office of Nuclear Safety (ONS) is reviewing the Overall Safety Manual (OSM). The OSM is a four-volume manual that presents a generalized approach to the nuclear safety analysis of plutonium-fueled space nuclear systems with supporting technical models, data, and procedures. The objective of the OSM is to provide standardized guidance to the individuals who must perform the risk and environmental impact analyses for the space missions.

This task is to provide technical support for the ONS review of the OSM, placing speclal emphasis on the risk models. The review will include an evaluation of the overall risk analysis methodology presented in the manual and the technical rationale supporting that methodology. The evaluation will consider the assumptions, adequacy, and limitations of the models for the overall analysis. The evaluation will al so address the methodology for determining the source term as well as the uncertainties and confidence level of the determined source term.

The findings of the review and recommendations for application of, and changes in, the OSM will be documented in a report which identifles how the review was conducted and provides technical support for the findings and rationale for recommendations. 


\section{Chapter 1. Introduction}

(1) Page 1.0-2. This is an extremely short introduction for such a voluminous volume. A great deal more could be said in this simple onepage chapter on the overall structure of the risk approach, the components of the analysis, and how they are fitted together.

(2) Paragraph 4 on this page indicates that specific examples of applying the models to risk analysis are provided in OSM, Volume 4 . Volume 4 has been updated and this is no longer true.

\section{Chapter 2. Model Summaries}

(3) Pages 2.0-1 to 2.0-3. These pages seem more appropriate for the introduction (Chapter 1) than this chapter. These pages start to lay a reasonable basis for how the analysis is put together. It could be extended by illustrating the type of information that is desirable and the type of information that, in fact, can be generated from Risk 11. A simpler figure could be used in the this chapter to illustrate the analytical process that is being proposed, and a more detailed figure might be presented in the applications volume, such as Volume 4 used to be.

(4) Page 2.0-3. The third item in the column headed by "Vapor source term" is illegible. Also, the three items at the extreme left-hand side of the diagram seem redundant with what follows. For example, one of the three terms is "source term definition," but a later column shows six types of source terms. Is "system fallure" covered by "ascent fallure"?

(5) Page 2.1-2. paragraph 1. Although the reader is advised to refer to Volume 4 for probability calculations, these are not to be found there. While Risk 111 is in Volume 4 , it is not referred to here.

(6) Paragraph 3. The physical explanation here is good. However, it is not clear how this information is used later on.

(7) Page 2.1-3. What is the relation between the probability that the RTG is not intact and that fuel is released from it? Are they always equal, or are there some cases where they are not? If the former statement is true, then we have redundancy in the first equation. The same question applies to the other three pairs of probabilities in this equation.

(8) What is meant by "free" is not defined, so the initial state is somewhat unclear. This applies to $S_{2}$ and $S_{3}$.

(9) It would be helpful on this page to state which terms are vector matrices and which are square. At present, this leads to confusion between equations 2.1-1 and 2.1-5. 
(10) Page 2.1-5. It is not clear what is meant, in line 8, that "the diagonal element (of the upper right-hand corner of the matrix) depends on the sum of the corresponding row". Is it the sum, or is it some function of the sum? If it is the sum, why is this so? In general, the physical reasoning behind this matrix is far from clear.

(11) Why is only the state-to-state portion of the matrix used in this manual, after some trouble had been taken to build the total matrix?

(12) It is inadequate to state that the probabilities are derivable from Volume 4, especially since as noted el sewhere in this review, th is volume is far from easy to use. In fact, there is not a single summary of what probabilities have been used and why these numbers were chosen.

(13) Page 2.1-6. line 2. Use "represents".

(14) This is a page where some diagram would be helpful to the reader because of the theoretical nature of the discussion.

(15) In the first equation, why are $m$ levels used after four levels were used previously?

(16) The equations 2.1-7 and 2.1-8 come out of the blue with no explanation as to how they relate to previous equations.

(17) Equation 2.1-8 is somewhat fouled up. The left hand side should be subscrlpted with a $k$.

(18) What is meant by "the most fundamental level of the fuel system"?

(19) In the line before equation 2.1-9, the word should be "release."

(20) In the last paragraph, the meaning of the sentence beginning "In a manual..." is unclear. Are the authors saying that the above equations apply to a nonmanual (presumably computer, al though this is nowhere specified) calculation, and that average probabilities apply to a manual calculation? As well, the relationship of the mean probability to the fuel inventory is not specified.

(21) What is meant by "degenerate" in this context?

(22) Page 2.1-7. line 1. It is stated that results are independent of the number of sources and cells, but no proof is supplied of this. Is this related to "degeneracy"? On the next I ine, the concepts of inhalation and ingestion come out of the blue. We were discussing source terms here, not pathways.

(23) The second sentence in this paragraph is confusing. 
(24) In the first definition following Equation 2.1-10, S should be s. There seems to be an erroneous statement in section 2.1.2. $P_{i}$ as defined does not give a "expected fraction" of the total fuel inventory which is in a fuel releasing state. From Equation 2.1-9 on page 2.1-6, it is clear that $P_{i}$ gives only the mean probability for fuel release and no information on expected fraction. The fact is that this probability could be extremely small, yet the total inventory could be in a fuel releasing state -- if the s specified on page 2.1-3 identifies all the potential release states.

(25) Why are the probabilities binomially distributed? Is there a physical basis?

(26) What is the relation of equation 2.1-10 to the probabilities in equation 2.1-1? If they are the same, it should be so stated. By this time, the reader is struggling under many probabilities, some of which seem to overlap others.

(27) In equation 2.1-10, are the items $C_{k}$ and $C_{m}$ the same as in equations 2.1-7 and 2.1-8? If they are, what is the significance of the brackets in the latter two equations?

(28) In general, the entire section 2.1.1 is confusing, with little physical explanation of the definitions or equations.

(29) Paragraph 2, line 4. Use "released".

(30) In the last sentence, it is stated that results are dependent on experimental data, which is obvious, but no experimental data are shown.

(31) In the line preceding equation 2.1-11, where does $n$ appear in the equation? In addition, the equation seems to come out of the blue. No reference is made to previous equations. We al so question the usefulness of this equation. Fuel is either released and we have a source term or there is no release and we have none. Expected quantities may not be relevant. It would seem that probabilities and effects (source terms) are being mixed too early in the analysis.

(32) In this equation, we have more evidence of the proliferation of subscripts. No effort has been made to relate subscripts of one equation to the next. In particular, a new subscript $r$ is introduced without explanation.

(33) Page 2.1-8. Equation 2.1-12 is superfluous.

(34) In paragraph 1, reference is made to a personal communication, which should be publicly avallable by now, after a lapse of nine years. Incidentally, this communication is the only reference in this subchapter since 1972.

(35) The changeover to a discussion of particle sizes on this page is jarring. The rest of the subchapter deals with probabilities, and the relation of the two subjects is unclear. 
(36) Paragraph 3. Starting at the bottom of this page and continuing on to page 2.1-9 the scaling by energy presents some difficulties under certain conditions. Look at Equation 2.1-13 on page 2.1-9 as it relates to Table 2.1-3 on page 2.1-17. How does one actually use the equation in scaling? Take the case where $v^{2} / v_{0}{ }^{2}$ is greater than or equal to $1 / w_{i}, v_{0}$. Then the fraction in that size range is greater than one.

(37) In Volume 3, Chapter 4, Appendix A, there is a large mass of data on impact tests. Do these tests verify these relationships?

(38) Page 2.1-9. More discussion should be provided on the assumption related to fuel inventory release. The assumption of $10 \%$ is not unrealistic, since it can underestimate the problem at most by a factor of 10 but may significantly overestimate the problem. The significance of this in relationship to other analysis uncertainties is great.

(39) The subchapter--and it would have been better to call each subchapter a chapter since there are only two chapters in the entire vol ume--contains no integration or summary, so the relationship of all the equations is unclear.

(40) Page 2.1-11. It is not clear why each of the five sequences shown has exactiy the same five events. The meaning of "optional sequence" is al so unclear; it is nowhere in the text. The relationship of this and the next three figures to the text is nonexistent.

(41) What are the re-entry angles mentioned here, and why are there exactly six? They are not noted in the text. Are there only 21 fallure sequences? Can this be proved? Again, no relation to the text.

(42) Page 2.1-15. The physical meaning of the last five terms in this table is not given. Without it, the reader cannot evaluate their effect on particle dispersion.

(43) Page 2.1-16. Table 2.1-2. No uncertainties are presented for any of the data. An explanation of the units in dissolution rates would also be helpful. The variation in significant figures, al though not very important, should be made more realistic. Particularly, the four significant figures for PMC fuel dissolution rate in sea water as opposed to the one or two significant figures for other dissolution rates seems questionable.

(44) In the footnote to this table, it is unclear why a one-year average was chosen, and what the values of 100 and 550 days mean.

(45) Page 2.1-17. Table 2.1-3. Five significant figures are used. This seems excessive. Again, no uncertainties are shown. The significance of the two velocities shown in the two footnotes is unclear. Why they are different is unexplained. The reasoning behind the size ranges is obscure, especially since almost all the weight is in the largest size range. Finally, in view of the mass of data it would have been better to put it all on a graph. 
(46) Page 2.1-1. Would additional and more recent data analyzed by WINDIF provide any more rel lable estimates and ranges of uncertainty for the launch area meteorology? This subchapter generally seems to be a recapitulation of material in Volume 3 .

(47) Page 2.2-6. The data in this table are quite interesting but would have been better presented as a graph.

(48) Page 2.2-8. The meaning of these classes is mentioned in another volume, but not here or in the text. Why not? Also, they are referred to as classes 1 through 7 el sewhere. Are they the same as these?

(49) Page 2.2-10. The regional demographics were from census data that were collected prior to 1970. This could mean that they are probably at least 20 years old. One might question whether more recent data would add significantly to the analysis.

(50) Page 2.2-11. This table is almost completely useless, since the sectors are not identified and the distances involved are not shown till the final page. The table seems to have been copied from a source where these explanations are given.

(51) The implications of this subchapter are not shown. The variability in data is not presented.

(52) Page 2.3-1, equation (unnumbered). We assume the angles are given in radians. The equation is not really necessary since the figure is provided.

(53) Paragraph 2. There seems lit+le reason to present the discussion of the 14 Koppen categories in this section, since any analysis would have to be done using the Turner-Pasquill classification system.

(54) In Table 2.3-2, no explanation of the classifications is given. If compared with Table 2.4-2 on page 2.4-10 and Table 4 in Appendix C (page 11) the classifications Iisted BWk and Bcf do not exist in the other tables. A category Cbs apparently has been omitted. Classification Daw is classification Dwa in Appendix C. With so many apparent typos, it is almost impossible to follow the presentation.

(55) Page 2.3-2, paragraph 1. On line five, reference is made to seven stability classes, but Table 2.3-2 has 14 . We suggest the seven are the Turner-Pasquill ones. The 14 are Koppen categories.

(56) On line 8, reference is made to an extensive statistical analysis, but the purpose of the analysis is unstated.

(57) Paragraph 2. The implications of the assumption about the inversion base, or what it is physically, are unstated.

(58) Paragraph 4. The relationship between rock and soil fractions and the impact is not stated. 
(59) Page 2.3-3. As usual, there is no summary of the major conclusions, or the relation of this section to those which preceded it. Each section is in a watertight compartment.

(60) Page 2.3-5. This figure is difficult to read.

(61) Page 2.3-8. This mass of data is confusing without an explanation. Again, too many digits and no uncertainties.

(62) Page 2.3-9. As in the preceding comment, a graph would clarify matters considerably.

(63) Pages 2.3-9 and 2.3-10. Tables 2.3-4 and 2.3-5 on these two pages should be made consistent with Figures $2.4-4$ and $2.4-5$ on pages $2.4-8$ and 2.4-9. Both appear to be based on similar meteorological categories, except in the tables they are identifled as $A$ and $G$ while on the figure they are identified as 1 through 7 . The comparison may be obvious but the inconsistency serves no purpose.

(64) Page 2.3-12. Graphics of some sort would help. Again, no uncertainties. Why use classes 14 and 15 if they are almost all zeros? Too many digits are used.

(65) Page 2.3-13. "Surface" and "intermedlate" fractions are not defined.

(66) Page 2.4-1. Orbital inclination seems to be defined graphically only in Vol ume 4, Appendix A, pages 5-7.

(67) Page 2.4-2. The objective of the calculations leading up to equation 2.4-5 is obscure, because equation 2.4-6 can be derived by integrating over the appropriate limits.

(68) Equation 2.4-7 is nearly incomprehensible. Some reasonable physical explanation of the equation would be helpful. Also, the subscript $j$ is not defined until one gets to Table 2.4-1 on page 2.4-4. This might be explained a little earlier.

(69) Page 2.4.3. As usual, no conclusions, uncertainties, or sensitivity analysis.

(70) Page 2.4-4. In the title, use "random". Also, these characteristics are not used in calculating probabilities; the probabilities are calculated separately. In entry 9, use "population".

(71) Page 2.4-5 through 2.4-9. All of these figures tended to imply greater significance to the curves than actually exists. In essence, the figures are histograms with 10 bars, one representing an increment of equal latitude band. With this in mind it is difficult to see how, in Figure 2.4-2 on page 2.4-6, a class 1 impact probability is shown as a line between 80 and 90 degrees of inclination, yet the limits of information would be associated with the latitude band ranging from approximately 65 to 90 degrees.

(72) Page 2,4-8. What are the implications of this graph? 
(73) Page 2.4-9. The y-axis should be labeled "occurrence probability."

(74) Page 2.4-10. The meaning of this table, as well as its relation to the two previous graphs, is unclear. Also, the bands used here are not the same as those used for population, making correlation of the two data types difficult.

(75) Page 2.5-1. There should be some consistency or at least some explanation why the model used here is somewhat different from that presented in Appendix D and both are different from that one used in Volume 4. These variations in models may be necessary or insignificant, but at least some comment should be made about the differences.

(76) Equation 2.5-1. The subscript in the term containing y should be $y$.

(77) Page 2.5-2. equation 2.5-2. Is a factor $r$ missing in the second term?

(78) Paragraph 1. It is indicated that the standard deviations (including $\sigma_{x}$ ) are obtained from reference 2.5-2. $\sigma_{x}$ is not given in that reference and, as far as we know, is simply not avallable other than as a result of making assumptions of similarity to $\sigma_{y}$ or $\sigma_{z}$.

(79) Equation 2.5-3. to is not defined.

(80) In equation 2.5-5, the typography in the last term seems strange. The belated explanation of $t_{0}$ is completely unclear and jargon-laden. Also, is this quantity the same to from the previous page?

(81) Pages 2.5-3 and 2.5-4. The tilting plume model with multiple reflections, as used in this section, may be inconsistent with the treatment of deposition used on page 2.5-4 if source depletion is not formally treated.

(82) Page 2.5-4. paragraph 1. Are there references on the topic other than the one given? Has this one been verified experimentally?

(83) Equation 2.5-9. It should be pointed out that subscript i refers to particle sizes and $N$ is the maximum of particle sizes.

(84) One should provide an explanation why isopleths are calculated. This shows the need for an overall physical description of what is being done. In general, isopleths are not elliptical even for single particle sizes or vapors.

(85) Page 2.5-5. The bracketed term in Equation 2.4-12 should be to the 1/2 power.

(86) Page 2.5-6. In Equation 2.5-16 it appears that the $p$ in the final exponential term of this equation should be deleted.

(87) In equation 2.5-18, there is a problem with typography. The graph in Appendix $D$, page 20, connecting all four of these equations, should be referred to. 
(88) Page 2.5-7. From where does the boundary of four microns come from? No references or experimental data are supplied.

(89) Page 2.5-8, paragraph 1. It is clearly Inadequate to state that part of the source term is treated with a computer model without specifying the basis for that model, its assumptions, etc.

(90) It should be simply stated that the transport of small particles is assumed to be similar to that that has been observed for stratospheric weapons debris and can be characterized by worl $\mathrm{dw}$ ide strontium-90 deposition. However, the discussion presented here is much better than a discussion of a similar application in Risk lll. Of particular significance is Equation 2.5-22 which should have been used at a similar point in Risk 111 , but was not.

(91) Line 5. We are sure that readers will note that the date here is 1965 , and that 18 years have passed since then.

(92) In the same line, Figure 2.5-2 is stated as being one Gaussian curve, but it clearly is the sum of two. We are not convinced this is the only way to fit the data. We agree that the assumption about Gaussian curves is probably reasonable, al though Figure 2.5-2 clearly shows that values at the equator are not zero. In fact, they are about equal to the maximum in the southern hemisphere.

(93) Equation 2.5-22. This equation comes from out of the blue, with no indication of how it is related to prevlous equations.

(94) Page 2.5-9, paragraph 1. An apparent deposition velocity is presented that has been calculated from the deposition of fallout in rain. This information is well over 15 years old and one might question whether it should be updated. More importantly, a different deposition velocity of $0.01 \mathrm{~m} / \mathrm{sec}$ is assummed in Risk III. The tropospheric half-time used in Risk 111 would imply a deposition velocity of approximately $0.008 \mathrm{~m} / \mathrm{sec}$. There is a real need for consistency.

(95) The relation of the velocity to beta activity is not shown explicitiy. The same comment applies to the second sentence dealing with the relation of air concentration to velocity.

(96) Equation 2.4-6. This equation should have a minus sign, not an equal sign. Has this mistake been carried into the calculations?

(97) Page 2.5-10, paragraph 1. The "model B" code is really rather old. The modification was made because of the computer capabilities that were avallable in the late 1960s. It would seem that we could do much better now.

(98) In the second sentence, the purpose of the modification is well-stated, but how the modification was accomplished is not mentioned.

(99) Paragraphs 2 and 3 . These do not adequately explain the codes. 
(100) Paragraph 4. What is meant by "spectral polynomials in the altitude," and how were they calculated?

(101) Page 2.5-13. The dispersion parameters shown in this graph (Figure 2.5-1) are taken directly from "Meteorology and Atomic Energy" for continuous emissions. In Appendix D there is a modification for puff releases. Why wasn't this used here?

(102) Last paragraph. In Table 2.5-1, use "microns." What does the listing of -0.334 three times mean?

(103) Eigure 2.5-3. The derivation of this graph is unclear. As well, the maxima do not seem to be at $45^{\circ}$, as is implied in the text or the previous figure.

(104) Iable 2.5-2. This table is unclear. Presumably it is based on the equations of Figure 2.5-2, but exactly how is not shown. Without an indication of what the bands mean, there is no way the reader can relate this to the previous figures without fllpping to the next page.

(105) Pages 2.5-19 to 2.5-21. Figures 2.5-4 through 6 are obscure. The reasons for choosing the three latitudes is equally obscure. As usual, no attempt is made to explain the implications of the calculations.

(106) Page 2.5-18. Why are these latitude bands different from the ones used in previous sections?

(107) Page 26-6-1. paragraph 1. A good physical explanation--th is clarity should be used throughout.

(108) Paragraph 2. Since Appendix E contains a discussion of other models and the IImitations of the present one, it would have been useful to refer more clearly to these facts in this paragraph. The first sentence, as presently written, is confusing.

(109) Paragraph 3. What is the "improved solution"? If it is referred to in Appendix $E$, no page reference is given. We have been unable to find it easily. Does the solution improve the results with respect to experiment? Since no experiments have been mentioned, it is difficult to judge.

(110) Equation 2.6-1. Essentially says nothing. It would be better to refer to Appendix E.

(111) Paragraph 2. Iine 2. Define surface layer more precisely. How is the concept used? On line 5, write "which creates turbulence." On Iine 7, how big is this density gradlent? Does it affect the calculations? On Iine 11, what is meant by the statement about less stability? On line 12, explain current shear. The word should be "thermocline." In general, many of the terms in this paragraph are used either loosely or in a confusing manner.

(112) Paragraph 3. Why are only three of the seven variables of equation 2.6-1 required? 
(113) Page 2.6-3. paragraph 1. The authors state that the reference they clte" gives a range of values but then condense this range into single values. The basis for this is not given. Since there has been an attempt to take account of natural variability elsewhere, why is it el iminated here?

(114) Paragraph 2. How "representative" values were chosen and why variabilities were el iminated are not clear.

(115) Paragraph 3. Again, huge averaging is done with ilittle justification.

(116) Paragraph 4. Again, averaging with no justifications or references.

(117) Paragraph 5. No diffusion model has yet been presented, so it is presumptuous to state that it has been used. Equation 2.6-1 is not a model, only a listing of terms.

(118) Where does the integration period of one year come from? What does it mean in terms of calculations? What is the data source?

(119) Page 2.6-4, paragraph 1. Why were no conclusions drawn from the calculations? The reference to Appendix $E$ is useless unless some indication is given on how to use it. An example would help here.

(120) There is no attempt to incorporate the results of Volume 3 in this section; how do they relate to the assumptions made here?

(121) Paragraph 2. There is nothing inherently wrong in using the same parameters for fresh and sea water, but some experimental justification is required. Few readers would be convinced on the basis of a bold assertion.

(122) Paragraph 4. It seems like a good idea to transform the computer output into more easliy handled forms.

(123) Page 2.6-5. The algebra in this part is much more understandable than in some other sections.

(124) Page 2.6-6. paragraph 1. This is a reasonable explanation, al though somewhat long. The document needs many more explanations of material like this. However, the reason for assuming a one-year period remains unstated. What would happen if other periods were used?

(125) Equation 2.6-8. This equation is not obvious in its derivation. Its physical basis should be explained.

(126) Equation 2.6-12. Units for $W$ should be watts, not $\mathrm{cm}^{3}$.

(127) Page 2.6-8. paragraph 1. Line 1. The term "parametrics" is jargon; can something better be used, like "calculations"? Some recapitulation of the results of Section 2.1-2 is necessary here in order to avoid flipping back and forth. 
(128) Paragraph 2. What is the main physical reason why the two sets of lines in Figure 2.6-3 are so different? How is fresh water factored in? In line 3, the mean particle diameter can be based on volume, area, or other factors. Which is used here? How do any differences play a role? In general, the implications of the graphs and equations mentioned in this paragraph are not discussed.

(129) Paragraph 3. As noted above, this ground concentration is dependent on computer programs whose assumptions are not given in the text. This discussion should direct the reader to where in the text these models are explained.

(130) Page 2.6-9. paragraphs 1 and 2. Excellent physical explanation.

(131) Paragraph 3. Line 5. An w is missing. On line 7, the value of $75 \mathrm{~m}$ should be referred to page 2.6-3, where it is first mentioned. However, no justification is given for this depth or the other two depths. It is unfortunate that $\omega$ is used for both diffusion velocity and ground concentration in this section.

(132) Paragraph 4. We know that $\omega$ is not uniform over space, but we question the assumption about Gaussian behavior. From Model "B", in a downwind direction, it is not. In any case, the form of the distribution is not mentioned in later calculations.

(133) Page 2.6-10. equation 2.6-14. This equation seems trivial. What is the point of this?

(134) Page 2.6-11, after equation 2.6-17b. It seems pecullar that after going to the trouble of carrying an integral through various equations, it is reduced to a constant at the last moment. Also, a prime is missing from the sentence preceding equation 2.6-18 and in the equation itself. This problem could be handled by simply using $\omega$ to represent a suitably averaged value.

(135) What is the purpose behind plotting Figure 2.6-6? Surely plotting vol ume versus area for a presumed constant depth will always yield a straight line. In addition, there seems to be little, if any, relation to the elaborate calculations which went before.

(136) The equation following 2.6-18 appears trivial and obscure. In the following paragraph, what is the significance of the period of one year? Again, is it just arbitrary?

(137) In the seventh line from the bottom, there is an extraneous word "rel."

(138) Page 2.6-12, paragraph 1. The physical explanation given is confusing; can it be rewritten?

(139) Paragraph 2. This paragraph is equally confusing, with little indication as to the implication of the statements. There are no conclusions drawn in this section, and the reader is left hanging. 
(140) Page 2.6-13, reference 1. Has there been any update since 1969? For the second reference, have there been any changes in the last 23 years?

(141) Elgure 2.6-1. This is clear and useful.

(142) Iable 2,6-2. It is unreasonable to have five significant figures here when many of the constants which went into the equations are known to one figure at best. Probably all of the values for a are the same.

(143) Elgure 2.6-3. It seems curlous that the deep layer is between the intermediate and surface layer in terms of normalized concentration, but since no detalls of the calculations are shown, we can't comment

further. The text should comment on this.

(144) Page 2.6-15. Table 2.6-1 is a good summary. However, it would be better if the reasons why these were chosen were al so summarlzed.

(145) Page 2.7-1, bullet 2. What is "each environmental inhalation pathway"?

(146) Paragraph 2. The statement of claims made at the beginning of this page is simply incorrect. Many of the items stated to be calculated have not been, at least in a usable form.

(147) Paragraph 3. Have there been any updates of References 1 and 2 since 1969 and 1966? If not, the applicability of this model deserves comment or analysis. The statement could be made about most of the other references in this section.

(148) Page 2.7-3. paragraph 1. It would have been better to have presented these figures in this section as well as in an Appendix. Also, what is meant by long-term and short-term exposures? This concept comes out of the blue. Why short-term is used in preference to long-term is also inadequately proven.

(149) Page 2.7-4, paragraph 2. What is meant by solubility class $Y$ compounds as defined in this reference?

(150) Last line. Use "organs."

(151) Page 2.7-5, equation 2.7-3. For $D_{i}$, use "up to time t."

(152) Page 2.7-6. paragraph 1, Une 4. Use "500 day half-life," not hal f-time.

(153) Equation 2.7-6. It is not clear how the constant disappeared here. Choosing $B$ for two dissimilar quantities here seems unreasonable.

(154) Page 2.7-7. paragraph 1. On l ine 7, use "breathing."

(155) Page 2.7-8. Are these the inhalation dose pathways that were left undefined on page 2.7-1? They should have been presented on the latter page.

(156) Page 2.7-10, paragraph 1, Line 2. Use "be." 
(157) Paragraph 2. What is meant by "no isopleth will extend lateral ly more than the central plus or minus one direction sector"? The discussion leading to equation 2.7-10 and the equation are vague and confusing.

(158) Page 2.7-11, equation 2.7-11. By this point, we suggest that almost all readers are lost. The reason behind the choice of $R$ (there is a frequent use of this letter in many equations) is totally obscure.

(159) The authors have almost completely avolded one of the key questions of the whole manual: What is the probability of a launch accident occurring? Until an estimate is made, or some guidance is given on how to make an estimate, no realistic risk assessment can be carried out.

(160) Equation 2.7-12. This equation is presumably the key equation for estimating at least part of the risk, but it has been derived through so many questionable or unexplained assumptions that the ability of any person to interpret this equation is doubtful.

(161) Page 2.7-12. This discussion should have taken place earlier, to give readers an indication of the purpose of this section. The entire section is misordered, and the relationship of different parts is obscure.

(162) Page 2.7-14, equation 2.7-16. It is not clear why the value of 0.01 micron is used here, when up to now all the material less than or equal to four microns has been used. Is this a realistic or a conservative assumption?

(163) Page 2.7-15. The frequent use of step functions (Kronecker deltas) without justification seems unreasonable. Also, the first equation is trivial and could be expressed in words.

(164) We again have an example in which the calculations trail off without any conclusions. Considering the vast array of graphs and tables in previous sections, it is strange there are none connected with the bottom lines computed here. This is a significant omission.

(165) Page 2.7-16. reference 7. The only use of this is a single gratuitous sentence on page 2.7-4.

(166) Page 2.7-19. Use "organs," not "oceans."

(167) The quantity e should be $\varepsilon$.

(168) Page 2.8-1. paragraph 1. This is almost an exact repeat of the beginning of section 2.7. This seems pointless.

(169) The term "the results are presented parametrically" is jargon.

(170) Paragraph 2. We find no ingestion portion discussed in section 2.7.1, so the reasoning here leads nowhere. 
(171) Equation 2.8-1. To avold having to flip back and forth, the terms in . the equation should be identifled. This case is one of the few where quantities remain the same from section to section. In any case, this equation comes out of the blue. We cannot find a similar equation in section 2.7 .

(172) It should be noted that this equation holds only for a single point ingestion.

(173) Equation 2.8-2. There is an $f_{2}$ where an $f_{1}$ should appear.

(174) Page 2.8-3, paragraph 1. The real Ism of assumption of the ingestion of all material at time zero and the maximum dose rate should be discussed.

(175) Paragraph 2. What is the basis for the first sentence? Why are the doses to the intestinal tract not considered?

(176) Line 6. Reference is made to Appendix F. Which page or equation in this appendix is referred to? Since there are 36 pages in this appendix, a precise reference would be helpful.

(177) In general, this paragraph is confusing and obscure in explanation.

(178) The discussion in section 2.8-2 seems reasonable, al though some indication of the insignificance of other pathways would have been helpful.

(179) Page 2.8-5. Is there other work than that of Miller? Some is mentioned in Appendix $F$, but not here.

(180) Page 2.8-6, paragraph 1. This is a good discussion of the experimental evidence, something that is usually lacking in other sections. Unfortunately, it is impossible for the reader to reconstruct how Miller's values were recalculated.

(181) Paragraph 2. This paragraph is completely unclear. Where does the factor of $10 \%$ come from?

(182) Page 2.8-7. paragraph 1. Some reference should be made to the fact that data in Table 2.8-3 are from Volume 3, Table 2.7-1.

(183) Far too many significant figures again.

(184) Page 2.8-8, equation 2.8-10. The present treatment seems confusing. There is little connection to the previous equation.

(185) Equation 2.8-11. This equation comes from out of the blue, with no explanation.

(186) The bottom of this page is the first place in the whole document where the source of probabilities is mentioned, let alone analyzed. 
(187) Page 2.8-9. Une 1. This type of analysis was not mentioned in section 2.1 , and no results were ever presented. The present statement implies results are avallable, but they are not.

(188) Equation 2.8-13 is a key to determining the effects of an accident, but no information is presented other than the equation itself.

(189) Page 2.8-10. The purpose of the equations at the top of the page is unexplained. What is the meaning of the first, second, and other persons?

(190) Following Equation 2.8-16, the meaning of the sentence beginning "Since $\omega(A)$ is. . . ." is completely unclear. We do not know th is quantity is distributed in a Gaussian manner.

(191) The reasoning behind these equations appears to be faulty and gratuitous. Why is not the total activity $\mathrm{N}$ times the average activity, where $N$ is the number of people affected? This is assumed on the next page.

(192) Equation 2.8-18. No account has been taken of fuel which falls into the ocean or lakes, or land where no crops are grown.

(193) Page 2.8-12. section 2.8.2.2. It is reasonable to use the approximation of volume required to grow an annual seafood requirement, but readers should be alerted that this is an extreme approximation. Is it conservative or realistic?

(194) Page 2.8-14, equation 2.8-28. As in the previous subsection, it is not clear why the average amount ingested is not merely multiplied by the number of people. The same procedure as in the previous subsection is being followed; both are obscure.

(195) In this entire section, nothing is mentioned here about mixing or currents, al though this is outlined in some detail in another volume. What is the relationship between all these factors?

(196) Page 2.8-15. The implications of the paragraph beginning "It is assumed" are unclear.

(197) Page 2.8-16, equation 2.8-37. We have here an example of the same expression meaning two things. $A_{o}$ is here defined differently from page 2.8-9, yet they are related.

(198) In the material after equation 2.8-38, the third equation may be $2.8-33$ or something else, not 2.8-23.

(199) Equation 2.8-39. By this point, the calculations have become so complex as to boggle the imagination. Yet a case has not been made that all this complexity is needed.

(200) Page 2.8-18. The assumptions here seem reasonable for lack of other data. However, the variablity in the data should be discussed as well as the reasonableness of the discussions. 
(201) Equation 2.8-42. $\rho_{s}$ is defined differently here from page 2.8-13 in terms of units.

(202) Page 2.8-19, first equation. The exponent should be four. Both this and the next equation have too many digits.

(203) Page 2.8-20. It would be helpful to define the concentration factor at least once in simple words.

(204) Page 2.8-21. By the time the end of this subsection is reached, the thread of the argument has unraveled completely, and we can no longer determine what has been shown. As a result, Figues 2.8-9 and 2.8-10 mean nothing.

(205) Paragraph 2. There probably are estimates of areas covered by fresh water through the whole world.

(206) Page 2.8-22, paragraph 3. It is not clear what is meant by the assumption of seafood as being equivalent to fresh water fish. This appears contradictory.

(207) Page 2.8-23. The derivation of the vol ume $V_{0}$ is unclear, since one number leading up to it isn't given. The exponent in the equation should be 14 , not 12 .

(208) Again, the use of the word "parametrics".

(209) By the time the reader reaches the bottom of this page, he will be confused with so many concepts and equations put forth. This would be in a worthwhile cause if some type of bottom I ine were achieved, but Figures 2.8-12 to 2.8-14 say very little in an understandable way.

(210) Page 2.8-24. Does the average person really drink eight glasses of water a day? Is this related to ICRP standard man?

(211) Paragraph 3. Why is not the fuel vol ume neglected here? It is about two orders of magnitude smaller than the ingested volume. In any case, this entire paragraph is completely confusing.

(212) Page 2.8-25, equation 2.8-45. The derivation of this equation is obscure. How one proceeds from this equation to the next one is unknown.

(213) Page 2.8-26. The derivation, in analogy to the ones in previous sections, would be satisfactory if previous ones had been satisfactory. Development in both sections is inadequate.

(214) There are again too many significant figures in the constants.

(215) Page 2.8-28. As noted el sewhere, the references could be improved by the inclusion of page numbers.

(216) Iable 2.8-1. Where do these numbers come from? Is there any varlability?

(217) A letter has been left out of the last column in this table. 
(218) Also in this table, should the denominator in the first footnote be epsilon instead of $e$ ? If not, where does e come from?

(219) In Column 4, the m should be capitalized.

(220) The second footnote has a missing factor.

(221) Eigure 2.8-1. The $y$-axis is missing 10-2. Also, the constants determined from this graph seem to differ from those of column 7 of the preceding table by a factor of one million.

(222) Iable 2.8-2. Why is the time labelled as $T_{1}$ in the preceding table and $\mathrm{T}_{1 / 2}$ here? Is there an equals sign missing in the footnote? The meaning of $e_{1}$ is again unclear, as it was in the comment on the preceding table. Finally, the relationship of the values in this table to the preceding one is not clear.

(223) Eigure 2.8-2 should be presented at the beginning of this section, since it outlines the general methodology.

(224) Elgure 2.8-4. The significance of this figure is not clear. The same statement applies to the next two figures.

(225) Iable 2.8-4. What is "normalized" catch? The concept is statistically insignificant.

(226) Iable 2.8-5 is reasonable, but without some numbers it is not too helpful. In footnote 2, word should be "event".

(227) Figure 2.8-7 is unclear. The same applies to the next figure.

(228) Table 2.8-6 is again of interest, but without numbers, not too helpful.

(229) Page 2.9-1. paragraph 2. It is implied that accident events have been treated in Section 2.1, but only part has been treated. The probabilities of each event have not been calculated at all.

(230) We can find no use made of the equation at the bottom of the page. Then why list it?

(231) Page 2.9-2. In Figure 2.9-1, where do the values come from? What is thelr variability? How does this relate to the values in Appendix G? In Figure 2.9-2, the same questions could be asked. We al so cannot determine the quantity of activity. Also in this figure, the units on the $y$-axis are garbled.

(232) Equation 2.9-1. Since Appendix $F$ is referred to, it would be worthwhile to note that it is equation 9 in this appendix that is used.

(233) Page 2.9-3, paragraph 2. Much jargon is used here, such as "smeared" receptors. This paragraph is not well written.

(234) The pathways at the bottom of this page seem reasonable. However, this is a repeat of Ilistings in other sections. 
(235) Page 2.9-4. Stating that $A_{C}$ can be found from the equations listed in Section 2.5 is misleading. Extensive work on the part of the readers is required.

(236) Page 2.9-5. paragraph 1. Again, it is inadequate to refer to previous sections without even an attempt at an example of the conclusions. This may be because no example of the previous sections was provided in the first place.

(237) Page 2.9-6, equation 2.9-5. This section is inadequate without graphs, tables, or other explanation of the results.

(238) Page 2.9-7, equation 2.9-6. There is no explanation of this equation -it comes completely out of the blue. This situation is about the same for the following equation. More explanation is needed of how they fit in.

(239) Page 2.9-8, paragraph 2. Jargon is again used without any explanation. What is a "smeared population"? Does this mean average?

(240) Equation 2.9-11. Recovery time should be explained more clearly.

(241) Last paragraph. A report from Ederington of Sandia Laboratory Indicates that the recovery time does not vary i inearly with population density. Some reference to this report should be made.

(242) Page 2.9-10. This entire section is inadequate because of lack of explanation and results. Some of the equations may be correct, but the authors are far from convincing.

(243) Elgure 2.9-1 differs by a factor of about 10 from page 23 in Appendix $G$. Why is this so?

(244) We presume that the figures in this section came from Appendix G, but something should be sald about this. However, the origin of Figure 2.9-2 is a mystery.

(245) On all the figures, there is no indication of variability.

(246) Page 2.10-1. This section is interesting, but its relation to calculating risk is not evident as presented. It is the outline of a program, not a calculation.

(247) Page 2.10-2, paragraph 4. There is no reason for burying the assumptions behind the model in Appendix $H$. In any case, the relation of the model to risk analysis is unclear. In line 4, it is stated that the model should be expanded in fiscal year 1976. Has it or was it?

(248) Paragraph 5. A recommendation is made about a tracking system here, but no recommendations have been called for. It is clear this section has been cut out of a funding proposal.

(249) Page 2.10-3. Line 1. Use "candidate." On I ine 2, use "emissions." The entire paragraph is very vague. 
(250) No conclusions are made in this section, and the entire Chapter 2 ends without conclusions.

(251) Appendix A, page 8. The definition for $Q$ has "fuel" misspelled.

(252) Appendix B, title page. This is dated 1974, which will arouse many readers' suspicions. It has been our experience that few computer programs are physically kept for more than a few years, so it is likely that the instructions and codes could not be carried out now. Is there a way of verifying this contention?

(253) Page 1. paragraph 1. Risk 11 may be the model to predict nuclear risk from spacecraft, but if it is constructed on the basis of the rest of this volume, it will be difficult to understand.

(254) A report "A Mission Risk Model..." is referred to, but there seems to be no list of references. Is this the predecessor to the OSM? This report is not referenced in any case.

(255) Page 2, paragraph 3. The reader should be referred to page 23 when section 2.13 is mentioned.

(256) Paragraph 5. The reader should be referred to page 23 when section 2.12 is mentioned.

(257) Page 3, paragraph 5. The failure probabilities are not calculated in the main text. How does the program do them?

(258) Paragraph 6. This paragraph is completely unclear.

(259) Page 5-7. The drawings don't mean much.

(260) Page 10. What is meant by environments? This term was not used in this sense in the main text.

(261) Page 27. There seems little connection between the discussion in this section and the equations and data in the text. Without that connection, one cannot judge whether the construction of this code is valid or not.

(262) Page 28. This is a good, though brief, discussion of possible errors. However, it is unclear if the "several checks" to detect errors are those beginning on page 30, or whether there are other checks as well. In any case, there should be a reference on page 28 to the list on page 30 .

(263) Page 41, paragraph 1. A new concept, pods and peas, is introduced here but is not in the main text.

(264) This chapter is valuable, in showing how calculations can be performed. Unfortunately, there is no obvious connection to the procedure in the main text, reducing its usefulness. In particular, Table XIl is not immediately traceable to the corresponding values in the text. 
In going through the calculations (on unnumbered pages), at least two points of interest are noted. First, there seems to be at least two sets of results headed points risks from external radiation." What relation they bear to each other is not clear. Second, the "expected number of persons" exposed to radlation in the last table is apparently of the order of a millilonth or so. What does this mean? There should be some graphical way to show the results.

Although it was claimed earlier in the text that a manual method for calculating results would be demonstrated, this computer program is not that method. Because of the lack of physical guidelines, it is difficult for the reader to judge whether the results should be in millionths of a person, or a number ten, one hundred, or one thousand times as large.

(265) Appendix $C$. page 1. This appendix is far too long, and reads like a $\mathrm{Ph}$.D. thesis, not a research result. As well, its relationship to the other lengthly atmospheric discussion (Chapter 2 of Volume 3 ) is not mentioned. This appendix unfortunately has the look of being tacked on.

(266) The implications of "improving the model" In terms of risk are nowhere mentioned. What is the point of the improvement if we can't judge the results?

(267) A reference is made to a 1973 paper, but there is no list of references supplled.

(268) Page 2. The use of an otherwise unspeclfied computer code will leave many readers feel ing helpless.

(269) Page 3, equation 1. Use "sun", not "sum."

(270) What is the point of the solar attitude, since it is not mentioned in the previous list of variables? In general, the algorithm developed by Turner should be explained more fully.

(271) Paragraph 1. Line 5. Use "Ephemeris."

(272) Iable 1. What is the net radiation index? it is not defined up to now.

(273) Iable 2. The notation in this table is not defined.

(274) Page 4. This discussion should explain Turner's work more clearly. See our previous comment.

(275) Paragraph 3. The rationale behind these elaborate calculations is still not clear from the text, although someone familiar with the computer code may understand it.

(276) Page 6. The second and fourth bul let are not very clear.

(277) Paragraph 2. Line 1. Use "distributions."

(278) The purpose of this statistical work is not clear. 
(279) Page 7. Where does the value of 70 come from? It seems like an incredibly large number of moments.

(280) Page 8. This is an interesting discussion but far too long and far af leld for a report of this type. The point of it all is never stated.

(281) Page 9. paragraph 2. Line 4. Use "radiation."

(282) Line 8. Is "altitude" meant?

(283) Page 20. The ranking procedure is completely obscure. The purpose is al so lost here.

(284) Page 21, paragraph 2, line 11. Use "notable."

(285) Appendix D. Since one of us (JRC) participated in the formulation of this appendix, it is not reviewed here.

(286) Appendix E, page 1. This description reads remarkably like that in Appendix D. Alert readers will resent the repetition.

(287) Page 2. A good discussion of the models available.

(288) Page 3, paragraph 2. The description of the model limitations is very good. This procedure is not followed in much of the rest of the OSM.

(289) Eigure 1. This is clear and understandable.

(290) Page 7, paragraph 2. This needs rewriting for more clarity. As a result, Figure 4 is unclear.

(291) Paragraph 3. It is not clear how the final equation on this page is derived although most of the explanations up to here have been adequate. In particular, what is $\mathrm{N}_{i}$ ?

(292) Page 10. It would be helpful if all equations were numbered.

(293) Page 13, paragraph 1. It is good that some uncertainty is introduced into the calculations -- this is rarely done el sewhere in the document. Unfortunately, there is Iittle explanation of what Figures 6-14 mean.

(294) Page 23. Again, graphs are presented without an indication of what they mean physically. Generally speaking, masses of graphs (36 in this appendix alone) do not do much for the reader and often lead to confusion. It would have been better to boll down the results to two or three graphs, each carefully explained.

(295) Paragraph 5. Line 2. Use "ocean's."

(296) Paragraph 6. The object of this calculation is obscure. Where does the equation on the bottom of the page come from? 
(297) Page 45. This is the first time we have seen an actual problem being done. This is very helpful. The graphs are integrated with the text one.

(298) Page 51. There is only one reference in this list more recent than two decades ago, which will draw the attention of readers.

(299) Appendix.F. Since one of us (JRC) wrote this appendix, we will not revlew it here.

(300) Appendix G. Since one of us (JRC) wrote this appendix, we will not revlew it here.

(301) Appendix $\mathrm{H}$, page 2. The object of this appendix as stated in paragraph 3 is commendable, but has $11++1$ le to do with the rest of the OSM. One object of the OSM is to calculate the public risk after various recovery methods are used. This appendix concerns Itself with planning these methods. The two aspects are not the same.

(302) Page 5. The conclusions here show that the appendix is in the nature of a proposal (for fiscal year 1975), not a risk calculation. The reader has no way of telling if the proposal (which appears to be sound) was ever carried out and what its effect on risk calculations could be.

(303) Page 12. There is no indication of whether this system ever worked, or how results from Operation Morning Light or the recovery operation near Palomares affects the calculations.

(304) Page 19. Where did these values come from?

(305) Page 20. It probably would be better to use a term other than chapter for subdivisions, since this is used in the main text.

(306) Page 21. While economics is an important subject, it does not play a part in risk calculations as far as is known. This part is a consequence of this appendix obviously having been prepared for another purpose.

(307) Page 23, paragraph 2. The distinction between analytic and simulation is not clear.

(308) Page 24. Tables 1 and 2 are completely confusing and difficult to read, and there is little indication of what it all means.

(309) Page 26. As noted el sewhere, too many significant figures.

(310) Page 27. paragraph 2. It is not clear how these calculations rel ate to the rest of the document. Particularly, how this relates to section 2.9 is not evident. 
"(311) Page 30. It is a good idea to use an example of the calculations, something which is often not done el sewhere in the document.

Unfortunately, the values chosen are not adequately explained, leaving the reader hanging.

(312) Paragraph 3. Line 3. The value should be multiplled by ten. Why was the particular value chosen?

(313) Page 31. As is almost invariable in this document, there are no conclusions drawn either from the appendix as a whole or from the example on the previous page. This is most unfortunate from the viewpoint of comprehension. 
(1) Page 1-1. This is far too brlef. The reader should be provided with a more complete idea of what is to follow and how it is to be used.

(2) Page 2.1-1. In the two equations, neither $R$ nor $S$ is defined. Also, we presume that the angles are in radians.

(3) Page 2.2-1. In paragraph 1, I ine 4, the word should be "Nations".

(4) In the first two paragraphs, the relation between population statistics and density is not clear. Surely the two data bases are the same. If not, their difference should be explained.

(5) In paragraph 1 a cryptic reference is made to classifled data which will fail to enlighten most readers. Most will fall to see how population data could be classified, since it is issued publicly. We suggest that the entire discussion be dropped. Also in this paragraph, note is made that the data could be updated, but no indication is given that this has ever been done.

(6) In paragraph 3, it is stated that the data would be presented in different ways, allowing for different types of analysis, but the purpose of all of this is not stated.

(7) In paragraph 4, I ine 7, strike the words "not given for countries," and substitute "available only for previous years."

(8) Page 2.2-2. In paragraph 1, I ine 2, strike "was," substitute "were."

(9) In the second bullet, what is meant by "first order civil division"?

(10) The third bullet is not very clear. Even if it were clear, the purpose behind the calculations is not stated.

(11) Page 2.2-3, Line 2. Use "formulae."

(12) In the first formula, if $R$ is known then $P_{1}$ is always known. What was done when $R$ was not known?

(13) Also, $R$ is now the percentage rate of change, not the radius of the earth.

(14) In paragraph 2, what is meant by "number subdivision"?

(15) In the last equation, $r$ should be $R$. Also, is the dependent variable supposed to be R? In any case, this variable is of no interest; what we really want is $Q_{1}$ or a projection of it.

(16) Page 2.2-4. Tables 2.2-4 and 2.2-6 have their captions interchanged.

(17) It would be helpful if all pages, including tables and graphs, could be numbered. This would avoid confusion if the manual is taken apart. 
(18) Page 2.2-5. The concept of figure 2.2-4 is not mentioned in the text. What is the significance of "vertical distribution"? Presumably this means height or altitude.

(19) In general, this section suffers from a lack of interpretation of a huge mass of data.

(20) Reference 2.2-5, line 3. Should be "Piedmont".

(21) The following tables and graphs are a combination of both data and analyses. The mechanism and the purpose of the analyses are seldom clear.

(22) Iable 2.2-1. We are aware of little or no data showing the density for highly crowded cities, which class 14 and 15 refer to. Where does this data come from?

(23) Table 2.2-2. Far too many significant figures. This comment appl les to almost all the tables in this section.

(24) Iable 2.2-3. The units should be persons per square kilometer.

(25) Table 2.2-4. The significance of this table, and where it came from should be indicated. The concept of orbital inclination is brought out of nowhere.

(26) In this and the following two tables, why use class 15 if no area falls into it?

(27) Iable 2.2-7. We are not sure of the purpose of the urban and non-urban categories. What relationship does it have to the final calculations? Also, how do the authors take account of the fact that some cells have this breakdown and others do not?

(28) What do the numbers in brackets mean? This is not explained in the notes.

(29) In the notes to this table, the explanation attached to the two stars is difficult to understand. This comes about because sources of data are not clearly identified.

(30) Iable 2.2-8. title. Word should be "Density". This table seems to be redundant to previous ones. As mentioned above, why use class 15 if it al ways contains zero?

(31) Elgure 2.2-1. Good graph--explains much.

(32) Eigure 2.2-2. What is the point of this graph? It contains much of the data of the previous one.

(33) Eigure 2,2-3. How can we tell what proportion is urban or non-urban on the basis of Table 2.2-7, which does not show it for most cells? Besides, the text does not indicate that this division is relevant for risk calculations. 
(34) Elgure 2.2-3. The mechanism of going from Table 2.2-7 to this graph is. not clear. Most of the cells in the tables do not indicate the proportion of urban and non-urban.

(35) Eigure 2.2-4. What is meant by vertical distribution? Is this the same as elevation in later sections? The units (meters and people) should be specifled. In any case, this graph is not explained in the text.

(36) Appendix A2.2. In I ine 1, surely there are less than 1999 world capitals; are they referring to provincial capitals? In Iine 3, strike out "by city name and numerically by cells"; substitute "within cells in Table A1; al phabetically in A2." In I Ine 5, strike "has been added. 1t." In line 9, is the 1971 yearbook meant, rather than 1970, previously mentioned in reference 2.2-1. The sentence in which this yearbook is mentioned is confusing.

If the last two digits give the census date, we question the results. For example, in Table A1, page 1, the date for Pskov would be 1976, for Dugavpils 1970, but most of the other places in the Soviet Union 1971. This seems strange. Also, how Kingsley Davis fits into all of this is unclear.

(37) Iable A1. It seems strange that there are eight substantial cities which cannot be found on any map. Some explanation is needed.

(38) The C's in this table presumably refer to national capitals. This should be noted. However, some, such as Douglas, do not appear to be capitals.

(39) At the end of this table, it is implied that urban population is only 20 percent of world population. This seems low. There is al so the usual problem with significant figures. Finally, urban is misspelled.

(40) Iable A2, end. Urban is again misspelled.

(41) Iable A4. Write "country/territory," since many of the locations are not countries.

(42) Section 2.3. The purpose of this section is not clear. How does elevation affect risk? There is no indication of uncertainty.

(43) Page 2.4-1. The significance of this section, which should be closer to the beginning, is given only partially in paragraph 3 . How does soil affect risk?

(44) In paragraph 1, are the nine soil types generally agreed on, or are there other classifications? 
(45) In paragraph 2, what is the "soll-population analysis"? How do they affect each other or affect risk? Also in this paragraph, we don't see how it can be said that population data extend only to $35^{\circ} \mathrm{N}$, when the previous section extended it to the North Pole.

The discussion of one-third degree by one-half degree centroids comes out of the blue, since previous sections had dealt with cells of very different dimensions. What is the point of the change? Also, the statement about urban data is completely unclear.

(46) In paragraph 4, the purpose of bringing in the equations for re-entry is not shown. In any case, the symbols should be explained again so the reader does not have to jump from vol ume to vol ume.

(47) Page 2.4-2. In the first line, the value of $\theta$ is not a function of soll and population data; it is the other way around.

(48) In the second equation on this page (unnumbered), it seems that $\theta_{1}$ and $\theta_{2}$ are used as discrete variables; yet on the previous page they are defined as continuous variables. The sum should be an integral. Also, what is the variable in the second summation?

(49) Is the latitude-longitude cell the one of the previous section, or the one defined on the previous page? There should be some standardization here. The fractional abundance should be called the same as fractional distributions on page 2.4-2 of Vol ume 2 .

(50) Last paragraph. The sentence beginning "The total range of population" is a complete mystery.

(51) In the last equation, where does population enter into the calculations, and why does it, if it is really there? Several factors from this equation seem to be missing, making it unusable.

(52) Page 2.4-3. What is $\rho$ ? It is not defined. By the time the readers get to the last equation, they will be completely confused. The purpose of all the equations remains obscure.

(53) Why were the particular angles of re-entry chosen?

(54) Iable 2.4-1. A reference for this table would be helpful.

(55) Iable 2.4-2. These data should be presented in the non-uniform bands used in the prevlous section. The meaning of the numbers or their sums remains a mystery.

(56) Iable 2.4-3. What is the implication of the statement that soils data are missing in 175 centrolds? What is meant by the "urban frequency"? This table seems to be redundant with the previous one.

(57) Iable 2.4-4 through 2.4-7. The results of these tables are obscure.

(58) Elgure 2.4-1. This is a good figure. It should be referenced. 
(59) Page 2.5-1. The explanations in the two bullets are good. In the second paragraph, it should be stated that data were developed for every cell that contained oceans. In paragraph 3, no indication of uncertainties is given, or the possibility of other data sources.

(60) Page 2.5-2. paragraph 1. Elevation should be defined. Is this the same as vertical distribution used el sewhere? In the table, there is bound to be confusion since most oceans have $E=0$. Nonetheless, this page has one of the clearer method explanations.

(61) Paragraph 2. This is one of the few places in this chapter where limitations on the data are mentioned.

(62) Page 2.5-3, paragraph 1. We are not sure why inland waters were counted as land. This implies that the Great Lakes are all land, which seems strange. To go on to state that this lack of discrimination presented no problem seems even stranger.

(63) Is an ocean usually called a tidal plain? The text says that oceans were "partially" lost in this calculation procedure, but does not state if this was a large or small fraction, or what happened to the part that was lost.

(64) Paragraph 2. This paragraph is completely obscure.

(65) Paragraph 4. The idea of an example is a good one, but the one chosen was poor and unclear. It seems to be Iand in Iran and Iraq. In I ine I, the word should be "Scripps."

(66) Iable 2.5-1. As usual, too many significant figures.

(67) Iable 2.5-2 is a good summary of the previous table, but would be even better in map form.

(68) Page 2.5-4. This is a good explanation of ocean currents, but at least two questions remain unanswered: How is the fact that currents vary with depth, time of year, and other factors taken into account? How are the data incorporated into risk calculations?

(69) Iable 2.5-3. Good table; for one of the few times shows how data were gathered.

(70) Page 2.6-1, paragraph 1. A good explanation.

(71) Paragraph 2. What is the relation between cl imate and weather on a given day? It is not a simple one. 
(72) Paragraph 3. What is meant by "up to" seven stations? Does this refer to each of the 720 cells? Reference is made to a computer program which will not be accessible to most readers and therefore not verif iable. How is the problem to be handled?

It is also not clear what relation the stability classes have to koppen categories. Also, Appendix $\mathrm{C}$ of Volume 2 seems to contain yet more meteorological data, the relationship of which to the present data is unclear.

(73) Iable 2.6-1. Some reference should be made to Figure 2.6-1; otherwise, this is incomprehensible. Also, the symbols for these categories do not correspond to those in this table or to those in Table C-10 or Table 2.3-1 of Volume 2. In general, the treatment of these categories is completely confused.

(74) Eigure 2.6-1. There seem to be only $12 \mathrm{classes}$ here in contrast to the 14 implied in the text. Why is there a difference?

(75) Page 2.7-1, paragraph 2. What is the variability in the data and what year or years does it refer to? Also, meat and fish do not seem to be included here.

(76) Paragraph 3. Where does the value for arable land come from?

(77) Page 3.2-1. paragraph 3, line 2. Use "County."

(78) Page 3.2-2, paragraph 2. Where is the ridge referred to?

(79) Paragraph 3. Line 2. Figure.

(80) Paragraph 3. Line 7. Cypress.

(81) Page 3.2-6. paragraph 1. Figure 3.2-8 does not seem to be necessary. Neither does Table 3.2-1.

(82) Page 3.2-10, paragraph 2. Explain "piezometric".

(83) Page 3.2-19, paragraph 3. The data are as much as 22 years old, and should be updated. The same applies to the data mentioned in the next paragraph.

(84) Page 3.2-24, paragraph 2. Explain the temperature lapse rate.

(85) Page 3.2-29, paragraph 3. Use "Missile."

(86) Page 3.3-1. Will the population data be used in calculations?

(87) Page 3.3-2, paragraph 2. Now 1980 data can be directly used, without updating old data.

(88) In the table, to what year does the data apply? How variable are the data? 
(89) Elgure 3.3-2. The background of this graph is unreadable.

(90) Elgure 3.3-3. There is no apparent purpose to this figure.

(91) Page 4.1-1. It is stated that the data will be periodically updated. Has it been?

(92) Appendix A4.1. The purpose of this appendix remains unclear. The integration of the data into other parts of the OSM is not done. On page 2.1-9 of Vol ume 2 the same concepts are discussed, but this appendix is not explicitly used.

(93) Page 5.1-1. Line 2. Use "Incorporated." 
(1) Page 1. Having a text of only two pages and all the rest as appendices is unreasonable. This page only forms the basis for unrelated appendices to be tacked together.

(2) Paragraph 1. Line 6. The deletion of the Instruction kit was a mistake. The statement that "adequate programs" exist to accomplish this task is incorrect, as shown in the comments on Vol ume 2.

(3) Line 8. The procedures in the other parts of the OSM could in principle be done manually, but it is highly unlikely that anyone ever will do them.

(4) Paragraph 3. The time period of Risk II was never clearly speclfied, as far as is known. Why was one year chosen in the first place?

(5) Line 8. Use "1000 years."

(6) Page 2. paragraph 2. Use "described."

(7) Paragraph 3. Use "parameters" instead of "parametrics."

(8) The information supposedly presented in Appendix $C$ is not there. This appendix is a bibl lography, not calculations.

(9) Paragraph 4. Line 2. Use "C", not "D." The purpose of the blbliography is unclear, especially since it is not stated what part of the information is used in the text.

(10) Paragraph 5. Line 3. Use "D", not "E." There is I ittle purpose to be gained by including a proposal as opposed to data in this volume. Delete it.

(11) Since these two pages are supposed to be the main report (as opposed to the appendices), why are no results presented?

(12) Page 1-1, paragraph 1. This seems to be a repeat of Vol. 2.

(13) In general, this is a relatively straightforward section. The five steps identified on page 1-1 are clear and helpful since the text of the remainder of the Appendix has been, to some extent, developed around these steps. Better use could be made of these steps to structure the analysis.

(14) Eages 1-2.3. The figures (Figure 1-1) seem to be somewhat more complicated than necessary. A simpler set could probably be developed for each one of the steps identifled on page 1-1. 
(15) Page 1-4. This page presents the argument that the long-term risk due " to released activity is important and that models other than those identified in Risk II are significant. What is the basis for this? Somewhere there must be clear delineation of which pathways are important, for what periods of time, and how the signifiance of these pathways was determined. It seems appropriate to isolate a small portion of the overall model and show relative significance by simple calculations, yet we are left with only the bold assertion that longterm risk and new pathways are significant.

(16) Paragraph 2. Une 6. Use "thousands." However, no reasoning is presented as to why the calculations should extend thousands of years.

(17) Paragraph 3. In I ine 6, what are "wheels"? In Iine 8, one had the impression that a linear dose-response relationship had been used in Volume 2, although admittedly the reasoning was unclear. Has this now been changed?

The rest of this paragraph is so vague as to be unreadable. Finally, a surprise awalts in the last sentence, where the mean value theorem of mathematics is brought in out of the blue. What it means is unknown.

(18) Page 1-5. paragraph 2. What is the development plan referred to? Is it the five steps on p. 1-1, or something else? It is unclear just what is being said. In fact, two statements in this and the fourth paragraph on this page seem contradictory:

"The Risk III model as described in this report actually represents the first stage of a two stage model development plan."

"The Risk 111 model reflected by stage two of the development plan is fully described in Reference 1 and Chapter 2 of this report."

Finally, this paragraph is a reasonable explanation only if it is stated where these differential equations may be found in a group. This is not done.

(19) Paragraph 4. This is good reasoning, but only if the individual pathways are shown along with their associated risks. Some reference to the appropriate section would be helpful.

(20) Page 1-6, paragraph 1. Th is seems repetitive to what has gone before, as does the next paragraph. Both are too verbose and general. 
(21) Page 2-1. It seems strange to have stage two come before stage one, which is described in the next chapter. The rest of the page seems like an expanded version of the first chapter. One time is enough.

This section could be Illustated by a more appropriate state diagram together with the associated matrix representation. Much of the discussion is unnecessary. Figure 1 referred to in the third paragraph on page 2-1 is not labeled in the text -- we presume that this is the diagram on page $2-3$.

We take issue with the statement that starts on the bottom of page 2-1 and continues onto page 2-2:

\section{"The accuracy of the solution Increases as the time step is made smaller."}

The accuracy of the solution is not dependent on the time step but on the accuracy of the transition probabilities input into the stochastic matrix.

(22) Page 2-3, paragraph 1. There is a $\lambda$ missing in the matrix equation near the top of the page. The figure and the top matrix on this page would be much more effective if applied to the multicompartment model utilized in Section 5.0 .

The meaning of the matrix at the bottom of the page becomes clearer after some thought. However, further explanation in terms of the dlagram would be helpful.

(23) Page 2-4. The middle paragarph of this page indicates that "detalled information describing each element of these matrices and the data input required for this model is presented in Appendix A". This would be very helpful. Unfortunately, Appendix $A$ is not provided.

(24) Paragraph 4. This seems like a repetition of the prevlous paragraph.

(25) Pages 2-5, 687. Since these figures are never used nor even discussed in any detail, we wonder why they are present at all? The first two are repeats of graphs in Volume 2, with transfer coefficients added.

However, there is no indication of what the coefficients mean, how many there are, if they could be variable, etc.

(26) Page 2-7. Figure 2-2. This is an ambitious attempt to bring clarity out of complexity. Unfortunately, it falls.

(27) Page 2-8. This discussion would be of great significance if it led to or was based on calculations lllustrating the significance of various pathways. As it stands, it is only words. What pathways must be considered? What are the parameters to be used? How does the time frame of reference bear on the relative significance of various pathways?

(28) Page 3-1, paragraph 1. As noted above, it seems odd that stage two precedes one. In any case, the meaning of the stages is not shown. 
(29) Paragraph 2. Projecting times to $10^{11}$ seconds (approximately 3,000 years) is somewhat presumptuous. This rivals recorded human history and hardly seems within the reasonable boundaries of credible analysis.

(30) Paragraph 3. It is stated that specific activity factors are described in Section 3.1 above, but they are not there. All this section contains is a reference to a computer code. Has anything been done on the subject since the code was published in 1967?

(31) Paragraph 4. There is a reference to 45 microns. Is this really 4 microns as stated on p. 5-6 subsequently. If not, why is "vapor source term" defined in two different ways? Where did the assumed value for vapor diameter come from?

(32) Is there a competing model to the "box model"? The two references to this model are from 1968 and 1970. Has anything been done on the subject since then?

(33) Page 3-2. paragraph 2-4. The deposition patterns for a high altitude release generated by the modified version of the Model B computer code were produced in the late 160s (or at latest prior to 1972). Has the development of particle trajectory models remained static during this period? If vapor is less than 4 microns and if the high altitude particulate source is material greater than $45 \mathrm{microns}$, how is the material between 4 and $45 \mathrm{microns}$ treated?

(34) Where is the modified Model B code IIsted? Is it avallable?

(35) Paragraph 6. The cryptic reference to a "special model, "without any indication of what it is or how the reader can evaluate it, is unsatisfactory.

(36) In paragraph 1, how is the question of recovery treated in the aquatic model? Considering intact re-entry and shallow water impact (less than about 300 feet) recovery is not only possible but probable. How is this treated in the Risk III model?

(37) Page 3-3, paragraph 2. Some indication of the numbers involved would be helpful. The entire paragraph is vague.

(38) Section 3.2.5. The six pieces of information make sense, except that "persons affected" is vague. Is being subjected to a millionth of a rad deemed affected? Some definitions are needed.

(39) Page 3-5. In the explanation for $r$, the third line doesn't make sense.

(40) This equation implies that total risk both can be and is calculated, but this is not done anywhere in this appendix. In any case, we oppose reducing the mission risk to a single number, without providing the detalled intermediate pathway-probabllity-dose-population distributions -- as is implied by the equation. Mission risk should be reduced to a single point estimate (for simpliclty or convenience) but only if the intervening data are avallable for consideration. 
(41) Page 4-1, equation 4-1. This equation is completely garbled because some Greek letters have disappeared. What appear to be subscripts are not. A Greek letter is al so missing from the definitions.

(42) Page 4-2. The lack of an explanation of computer codes prevents readers from obtaining a grasp of what is going on.

(43) Paragraph 1. Although fuel types are supposedly described in Section 3.1 , they are not to be found there.

(44) Page 4-3 to 4-6. To present the detalls of decay as shown here simply confuses the radiological risk evaluation. The shortest half-life following the initial members of the chains indicated above is the 250,000 year hal $\mathrm{f}-1 \mathrm{ife}$ of $U-234$. The others have hal $\mathrm{f}-1$ ives ranging from millions to billions of years. To include these may be complete physics but only confuses the issue (and the calculations) from the standpoint of risk estimates.

(45) Page 4-6. There is no conclusion or summary to this chapter. Readers cannot tell what has been shown.

(46) Page 5-1. paragraph 1. Al though reference is made to Vol ume 2, no indication is given how the present analysis differs from the one there.

In addition, the text references the OSM itself (reference 2). This is unreasonable. Simply referring to the OSM with approprlate page numbers is sufficient.

(47) Section 5.1. paragraph 2. The text certainly does not describe this transfer process as is stated. All that the text does (page 5-34) is reference the U.S. NRC XOQDOQ Computer Code. This hardly describes an atmospheric transfer process.

(48) Section 5.1.1. High altitude releases are discussed, but there is no estimate of their probability. We do not find these estimates anywhere in the OSM.

(49) Page 5-2. This seems simllar to what was discussed in Volume 2. A problem with nomenclature starts on this page (Equation 5.1) where a parameter $R$ is introduced without definition. Clearly, it represents the radius of the earth, but later on in this section $R$ is defined again as a population risk factor, a resuspension factor, and an arbitrary distance from a release point. In addition, $r$ is defined as a concentration factor for vegetation. Some thought about definitions could lead to greater clarity and less repetition.

(50) Pages 5-3, 5-4. Why repeat what was said in Vol. 2? Figure 5-1 on page 5-3 is completely useless. It is almost impossible to even read the numbers for the various cells. If this is all the information that is provided, it must be made readable. If more detalled information is provided in the Appendix to Volume 2, then only a simple description of the data and where to find the detalls should be presented. There is also another occurrence of referencing the Manual. 
(51) Page 5-5 (table 5-2). There appear to be a number of errors or inconsistencies in this table. It would help if the table were more clearly explained. Some problems are

- The subset of shallow, intermediate, and deep ocean fractions sum to the total ocean fraction. However, the sum of the subsets for the land fraction (soll and rock) sum to 1. Thus, they represent fractions of the land fraction. Clearly, an inconsistency with the presentation for ocean.

- The fresh water fraction appears to stand alone, not being included in the land fraction or the ocean fraction (which together add to 1.0 ), but this fraction appears to be 2.2 per cent of the land fraction.

- The population density value of 62.99 for latitude band 9 appears to be in error. The value should elther be approximately 37, or the population or land fraction are in error.

(52) Page 5-6. paragraph 1. Reference 2 turns out to be the OSM itself. This suggests that this Appendix was prepared for some other purpose, and then appended to the OSM.

(53) Paragraph 2. No use seems to be made of Figure 5-2. It seems unreasonable to expect that particulates will fall in the latitude band in which they are released. Is there any proof of this? Finally, reference is made to impact probabilities in Table 5-2, but there are none. However, Figure 5-3 does have some.

(54) Page 5-6. paragraph 3. This ralses the question of what is considered a vapor. Here vapor is assumed to be less than 4 microns in diameter, but as mentioned on page 3-1, vapor is $45 \mathrm{microns}$. This should be clarified. The basis for the values in Figure 5-5 deserve more and better explanations than references over a decade old. At the moment, the data seems to come out of the blue.

(55) Page 5-8 and 9. Are Figures 5-3, and 5-4 really necessary? What purpose do they serve? They do not provide usable data for "by hand" analysis nor is there any discussion of their implication to mission planning. These figures certainly do not appear necessary for an understanding of Risk III. If they are presented in an attempt to provide information for someone to use, more accurate and readable forms would serve. If it is simply a presentation of examples, it should be so stated.

(56) Page 5-11. The equations shown are straightforward, but they do not show any influence of weather conditions, diffusion, etc. 
(57) Page 5-12. There should be a detailed discussion of the decision to relate concentration as a function of altitude to air density. It inserts a logical inconsistency with later presentations. Minor points first: In the presentation at the bottom of this page there appear to be two typographical errors. In the expression for $b$ there should be $a$ minus sign preceeding the exponential 4. Further, in the relationship for MT it appears that the exponent should be 17. These are not the major problems, however.

The real question is one of ground level air concentration, how it relates to deposition and consistency of the approach to the problem. In this section, the air concentration is related to air density. A more appropriate way to approach the air concentration problem is touched on later (page 5-42) where total deposition rate is assumed to be proportional to the ground level concentration times a deposition velocity.

The point is that the ground level concentration is at some later point related to the deposition rate by a deposition velocity. In this section the total tropospheric source is assumed proportional to the air density, which implies a different deposition velocity. The logic is inconsistent.

This proportioning by density yields a deposition velocity of $4.5 \times$ $10^{-2}$ meters/sec or, if corrected for the error in the equation at the bottom of page 5-12, a value of $4.5 \times 10^{-3}$ meters $/ \mathrm{sec}$.

Also, the assumption of a density-concentration-height relationship al so defines a deposition velocity-height relationship.

Possibly one might be able to show that such a relationship holds -but (1) it certainly has not been done; (2) it is not necessary for the model; and (3) it leads to a logical inconsistency with later development. In any event, this portion of the text and that portion starting on the bottom of page 5-18 and proceeding through to the top of page 5-33 need a consistent logic.

(58) Page 5-13, paragraph 1. The basis for the assumption about the varlation of half-lives with altitude is not given.

(59) There is no way to go from the equations IIsted to Figure 5-6. This is an inadequate way of proceeding.

(60) Paragraph 2. This seems to be a repeat of the treatment of Volume 2. Is there anything new here?

(61) Page 5-14 (Figure 5-6). Either the 15,000-foot or the 20,000-foot curve is in error. The area integrals of the two curves should be equal. Thus, the curves must cross as the others do.

The ordinate is mislabeled. The units are either $\mathrm{grams} / \mathrm{gram} / \mathrm{meter}^{2}$ or this should be defined as integrated concentration. 
(62) Page 5-15 (Figure 5-7). This Figure (providing for the latitudinal variation) is presented in Appendix D of Volume 2 (page 48). The curve is based on the simple assumption that the returning high altitude debris from space systems could be characterized by the observed latitudinal distribution of weapons test strontium-90 deposition through the end of the year 1965. Two questions occur: Is the comparison with the strontlum-90 from weapons debris still the only or most reasonable assumption? Are there no more recent data than 1965 that would be helpful to a definition of deposition? Regardless, some comments should be made in regard to the uncertainty in such a prediction. It appears from Appendix D, Volume 2, Figure 29 (page 55) that the uncertainty is estimated to be approximately a factor of 2 . Is this still a reasonable estimate?

It is important to note that the fallout pattern predicted in Figure 5-7 is for ground deposition and is not specifically related to airborne concentration. Thus, the discussion following page 5-13 must introduce a relationship between ground deposition and assume ground level air concentrations prior to the introduction of Figure 5-7. This discussion should clear up the questions that we raised regarding the assumption of an atmospheric distribution of concentrations on page 5-12, and would also clarlfy some of the questions pertaining to page $5-21$ and beyond.

(63) Page 5-16. Table 5-3. Where does this table come from?

(64) Page 5-17. At the top of the page where definitions are given, it would appear that the second item should be $f_{j k}$ rather than $F_{i k}$. Following Equation 5-17 where the definition is given a symbol has been omitted. The left hand side of equation 5-18 should be subscripted for consistency. By now, the argument has become so complex as to lose most readers.

(65) Page 5-18. At the top of the page in the definition for $R_{j}$ the units of "persons" are given. Clearly, from the equation that follows, if it is intended to equal $R_{j}, R_{j}$ is dimensionless.

(66) Paragraph 1. The world population is bigger than specified here. Also, what is the relation between Figures 5-8 and 5-4? There seems to be some connection, but it is unspecified.

(67) Paragraph 2. There is a leap in logic here which is unexplained. Prior to this the "risk factor" for high altitude releases was calculated, without any intimation that it was Iimited. Now a new equation (5-19) implies that ground levels have to be considered. A clarification is needed here.

(68) Equation 5-19. It seems somewhat awkward to go through the arithmetic here when the specific activity of the material is generally known. Thus, one need only multiply the ground level concentrations by a known specific activity. The definition on page 6-1 makes this analysis useless. After the equation, Avogadro is misspel led. 
(69) Page 5-20, equation 5-20. The physical basis for this equation is not evident. is $Q(0)$ a constant or not? How have the limits on the integrals been changed? There is a letter $Q$ missing from the definition of the last term. Also, the limits for the last term seem strange. There also appears to be some confusion in the definitions. The time integrated ground level concentration has no units but should be in units of time divided by volume. Unfortunately, these units are given to the ground level normal lzed concentration in a subsequent definition.

(70) Paragraph 1. The word ORIGEN is misspelled.

(71) Again, information is burled in a computer code that should be brought into the open.

(72) At the bottom of the page it seems totally unnecessary to go through the mechanics of integrating Equations 5-4, 5-8 and 5-10. One might simply say that the time integrated ground level concentration has been calculated for some specified time periods for releases in the mesosphere, stratosphere, and troposphere and are summarized in Figure 5-9.

(73) Page 5-21. paragraph 2. Results are supposedly shown in Figure 5-9, but this graph is not explained at all. The graph is supposedly derived from either the ORIGEN code or the preceding equation, but no indication is given as to how this is done. The relationship of the code to the equations is al so not discussed.

(74) Page 5-21, paragraph 3. This could certainly use some explanation, particularly when one understands that the removal from the troposphere is primarily the result of removal by rainfall. It is not clear how resuspension at ground level is included in the process. Further, since removal half-times of the order of a few weeks are used, while later on resuspension factors covering periods of time of several years are used, one can reasonably ask: How can a removal rate on the order of days reflect resuspension that is apparently on the order of years? The statement seems to fly in the face of logic. It may be true, but certainly deserves more than this simple statement.

(75) What is the difference between ground $\mathrm{plane}$ and ground level concentration? The terminology seems fuzzy here. 
(76) In equation 5-24 a t' is again introduced, without any explanation. It • is reasonably clear what is being done, but it $\mathrm{might}$ be explained. Also, it certainly seems that one could have foretold the need of deposition and introduced it into the model earlier as a compartment. We would like to see it defined as "deposition" or "deposition density" rather than "ground plane concentration".

This is the first place at which ground $p$ lane weathering removal rate is identifled. The significance of this weathering rate, its value, or the mechanism of its action is nowhere presented. Yet, apparentiy it is expressed in the graphics on page 5-24 (Figure 5-10). See our question about that graph below.

(77) Page 5-22 (Figure 5-9). This figure could be more reasonably presented as a table. There are six time periods and three releases. Thus there are really only 18 data points. It is reasonable to have three columns (one for each release, l.e., 30,000 ft., 135,000 ft., and 150,000 ft.) with a value for each of the various time periods. It is important to realize that without decay, the summation of the integrated concentrations for each of the releases should be the same. That is, each release, no matter what the helght, should accumulate identical integrated exposures. Thus the columns described above would sum to identical values. Also, the second value on the $x$-axis should be $10^{-2}$. Finally, the identification of the $y$-axis is not what is in the text.

(78) Page 5-23. This is the first page where an equation is presented for deposition. Because of the shortcoming of not initially structuring the problem properly, it requires that one differentiate the stratospheric inventory equation and then integrate it using a weathering removal rate. This segmented type of approach seems short-sighted.

(79) Equation 5-26. In the second large term within the brackets, the first exponential term should include $\lambda_{1}$ instead of $\lambda_{w}$.

(80) The conclusions drawn are murky. The results are supposedly shown in Figure 5-10. How one goes from the equation to the graph is not shown. Without a value for the removal rate and other values, the calculations wlll not produce numbers.

(81) Page 5-24 (Elgure 5-10). There is no place that $\lambda_{w}$ has been defined in terms of numerical value. Yet, these graphics imply a $\lambda_{w}$ with a value of approximately $1.7 \times 10^{-3}$ /year (a hal $\mathrm{f}-1$ ife of about 400 years). Is this elther reasonable or meaningful? The issue is simply not discussed.

(82) Page 5-25. What is the purpose of equation 5-29? No use seems to be made of it. Having both sides of the equation divided by $Q(0)$ adds nothing to understanding. 
(83) Equation 5-30 in the middle of the page could be much more simply written without the integral sign. In fact, it is later (see Equation 5-34 on page 5-29). Again, the lack of some coherent structure to the presentation leads to this apparent complexity.

(84) In the definitional statement following Equation 5-30, $r$ is given the dimensions of grams/meter ${ }^{2}$. This should be meter ${ }^{2} / g^{2}$ am vegetation.

(85) In the paragraph following Equation 5-30, why not simply explain that the ground deposition multipled by a "concentration factor $(r)$ " leads to the vegetation concentration. There is no need to add to the profusion of equations when simple statements are enough. In addition, there appears to be a small error in logic here. Since Equation 5-30 provides a fraction of the total deposition being related to vegetation, this portion must be treated separately in terms of the ground plane weathering removal discussed on page 5-21. That is, one cannot have a $\lambda_{w}$ related to the entire deposition while at the same time applying a $\lambda_{v}$ to some fraction of it.

(86) Finally, in the middle of this paragraph it should say the resulting "average" normalized vegetation concentraton is shown in Figure 5-11. In general, this section will have to be rewritten to make it understandable.

(87) Page 5-25, paragraph 4. As noted previously, the basis for the four micron dividing line is not given.

(88) Page 5-26 (Flgure 5-11). This figure should more closely follow the concentration curve presented in Figure 5-6 on page 5-14. Speciflcally, it is not obvious why the vegetation concentration in time periods between 10 and 100 years does not exactly follow (proportional to some fractional concentration factor) the concentration curves in Figure 5-6. They must at least exhibit a very similar shape. Possibly the 150,000-ft curve in Figure 5-6 is in error, since the tail shows a decrease with a half-life of about 10-20 years, where in fact the text glves a 5-year residence half-life to the mesosphere.

(89) Page 5-27. equation 5-31. While this equation is probably val id, it would be useful to have a reference. The use of only two significant figures in the constant is commended.

(90) Paragraph 1. It must be pointed out that Equation 5-3i relates to spherical particles or that $D$ (the particle diameter) is a characteristic diameter based on fall velocity.

(91) Paragraph 4. References for all the constants should be given. Are they all in reference 26 ?

(92) Page 5-28. Table 5-5. Is there a point to this table when only fuel of 4 microns diameter is being considered? Also, in the third I ine a pis missing. This table 5-5 is indlcated as reference 25. Unfortunately, there are two reference $25 \mathrm{~s}$ and this is the second one. The significance of fall velocity is not obvious. Why is it introduced? 
(93) Page 5-29. In the first paragraph, Equation 5-36 should be 5-32, Figure 5-i4 should be 5-12 and Figure 5-7 should be 5-6. The purpose and objective of this discussion is certainly not clear. The curves in Figure 5-6 are the result of an overall removal half-time which, for the troposphere, is not related to falling in the accepted sense. If one wishes an apparent fall velocity it may be calculated by noting that the mean residence time is simply $1.44 \times$ the half-life. Thus, considering the tropospheric compartment with a 10 day half-life and a helght of $10^{4}$ meters, one would get an apparent fall velocity of 0.008 meters/sec. This velocity is approximately equivalent to that of a 5 micron spherical fuel particle, but this has essentially nothing to do with characterizing the material as representing the inhalable range as indicated on this page. There should be real and rather detalled considerations that lead to the assumption that the material in the size range less than or equal to four microns is characteristic of the total inhalable range. This does not have to do with fall velocity nor environmental transport, but should be a result of the inhalation model. This assumption and the discussion of it is important but unclear in the presentation. It is misplaced here and is not a consideration related to the high altitude release of the larger particles.

(94) Paragraph 2. This again raises the question of the groupings of particles. On page 5-25 the high altitude particulate release is stated to be characterized by that material greater to or equal to four microns physical diameter. In this paragraph, it says that the high altitude release in the non-inhal able range is assumed to be characterized by $45 \mathrm{micron}$ particles. Yet the deposition patterns discussed later on this page were obtained using a distribution of particle sizes and Model B computer codes. What is the significance of the 45 microns?

(95) Again, we question whether some comment should be made regarding the Model $B$ computer code and the particle size distribution shown in Figure 5-13. This figure as well as Figure 5-14 (page 5-32) is at least 12 or 13 years old. Has nothing changed? If so, comment is in order.

(96) Paragraph 5. The OSM is again referred to itself, which is unreasonable.

(97) Fol lowing Equation 5-33 at the bottom of the page, the reference to Equation 5-29 should be 5-24. Equation 5-34 would be a preferred alternative to Equation 5-30 on page 5-25.

(98) Page 5-30 (Flgure 5-12). The graph paper for this figure has the scaling for the ordinates inverted. Thus it is simply impossible to use.

(99) Page 5-31 (Figure 5-13). Why is the lower cut off at three microns rather than at four microns discussed in the text? 
(100) Page 5-32. Figure 5-14. The purpose of this graph is unclear until "affected area" is defined. Most areas in a latitude band will have some deposition, so some cutoff has to be used. Also, the effect of water/land ratios has now disappeared. This should be so stated. This figure is in any case Figure 32 in Appendix D of Volume 2. What purpose is served by repeating it here?

(101) Page 5-33. Paragraph 3. There is a very significant statement made:

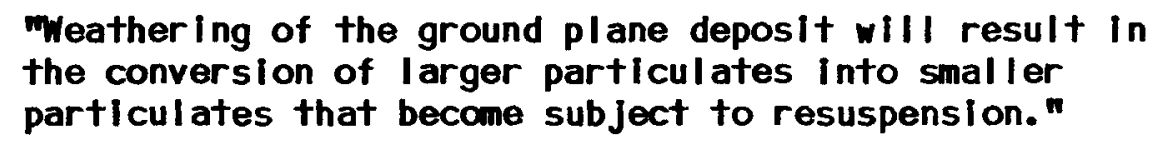

What data are avallable to support this conclusion, or is it simply a statement of opinion? In any case, how does it relate, or is it related to the immediately following discussion on resuspension? Were the studies of resuspension done in plutonium dioxide particles somehow related to the weathering conversion of larger particulates to smaller particulates? If so, how? If not, has something been overlooked? It is difficult to understand why this speculative and confounding statement is made without any further discussion or consideration.

(102) Equation 5-35. There should be a bar over the second term on the right hand side. In the following unnumbered pair of equations, there are too many significant figures. Also, the "greater than" and "less than" signs are missing. In reference 28, which is referred to here, the initials of the author should be C. L., not B.

(103) At about the middle of the page, where separate time frames are used for two different resuspension factors, it is possible, with in reasonable accuracy, to characterize resuspension by the simple sum of two exponential terms: $r(t)=10^{-5} e^{-4.95 t}+10^{-9} e^{-0.105 t}$. This is as good a fit as the two time period presentation given. Although not of great significance, writing $r(t)$ for a single time relationship avoids the confusion of a function such as $\Theta\left(t-\Delta t_{j}\right)$.

(104) There is a resuspension model presented in Appendix $D$ of Volume 2 . How does the model used here compare? Why was a new approach or new model used?

(105) Equation 5-36. There is no indication of the purpose of this equation, and no graphs or tables are prepared from it. What is the point? Also, there is no calculation of the ratio of resuspended particles to those which fell originally.

(106) Page 5-34, paragraph 2. Again, reference is made to a computer code which is probably not accessible to many readers. The authors outline what is calculated, which is helpful, but not the basic assumptions behind the calculations. What relation this code has to any other calculations in this volume is completely unclear. 
(107) The last paragraph refers to "fourteen world-wide climatological categories", yet Figures 5-15, 5-16, and Table 5-6 (on pages 5-35 through 37) indicate only seven stability classes (1 through 7 on the $f$ igures and $A$ through $G$ in the table). How do these relate? How are the data presented in Figures 5-15 and 5-16 to be used? At the bottom of this page it says that

\section{The varlability shown In Figures 5-15 and 5-16 relative to $\eta=90^{\circ}$ is not considered significant in the context of the error band of the entire analysis.}

Does this mean that the whole question of orbital inclination in regard to meteorological parameters is of no consequence? And if so, just how has this been shown?

(108) Page 5-36. Figure 5-16. The ordinate on this figure probably should be labeled something other than "Impact Probability." In any event, for any given inclination the probabilities should sum to one. Most seem of $f$ by somewhere in the range of 10 to 15 percent. Why? The meaning of the graph in terms of risk is obscure. The point of all of this has been lost.

(109) Page 5-37. Table 5-6. The two previous graphs had numbered stabllity classes; now we have lettered ones. Are they the same? This table unfortunately is not related to the two previous graphs, so what they all mean is a mystery. Without a brief definition of the classes, the reader is helpless. Finally, there are too many significant digits.

(110) Page 5-38, paragraph 1. For one of the first times in the entire volume, the possibility of uncertainty is mentioned. Unfortunately, there is no indication what the "error bands" referred to really are.

(111) Paragraph 2. This paragraph is completely mysterious, with no suggestion of what these runs were, what variables were tested, or what the "normalized" concentrations are. What is meant by "Integrated"?

(112) Paragraph 3. It says that calculations were made using the resuspension model described by Equation 5-35 through 5-37 of Section 5.1.1.2 and assoclated vegetation concentrations were calculated according to Equation 5-30. However, there is no val ue given to the vegetation concentration factor of Equations 5-30 and 5-34. We made an attempt to determine what is meant by comparing the figures, but unfortunately one of the figures is mislabeled. Both Figure 5-17 and 5-18 have exactly the same designation on the ordinate scale. From Equation 5-34 one would expect Figure 5-18 to be labeled in units of grams fuel per gram of food rather than grams per meter ${ }^{2}$ per gram released.

(113) Section 5.1.2.2. The entire meaning of this section is obscure. It presumably has to do with computing population exposure. However, the information is presented only as a group of equations, whose relationship to the equations which have gone before is not stated. Also, the information on resuspension of previous sections is not used, and the quantity $A$ is undefined. 
(114) In the first paragraph (regarding general population exposure) it is boldly stated that vanishing small concentrations at great distances are important. This is only true if it can be shown that the man-rem value is significant in relationship to the other exposures. All exposures should be considered, but their importance lies in the magnitude of dose in relation to other routes of exposure.

(115) Equation 5-38 is trivial. Simply stated, it says we have to consider al I the material released if we want to consider all the exposure. If Equation 5-38 is taken as exact, then the upper limit on the second integral is not arbitrary, but is in fact defined by the limit within which a relationship holds exactly. There is no need later, on page 5-42, to invoke the "mean value theorem of integral calculus." One can simply state that the total material released divided by the affected area is equal to the average ground concentration. This is true by definition and is obvious fact. The area of contamination is certainly not arbitrary any more than $R$ is arbitrary, unless one wants to accept that wis arbitrary.

(116) Page 5-42. This section could well have started with Equations 5-39 and 5-40. In fact, these equations could and should have been presented much earlier, around page 5-12, where Equation 5-12 was assumed. One would then have a relationship for air concentration using $V$ and $w_{0}$ Further, on pages 5-21 and 5-22 where ground level concentration was being developed, one would not have to go though the differentiation/integration step.

(117) There should be at least some discussion regarding the effective deposition velocity of $0.01 \mathrm{~m} / \mathrm{sec}$. The relationship of this assumption to other parts of the OSM should be explained. In Chapter 2.5 of Volume 2. (Page 2.5-4) an expression is provided for ef fective deposition velocity (Equation 2.5-8). A similar expression is presented in Appendix $D$ of that volume with a lower limit of deposition velocity of $0.002 \mathrm{~m} / \mathrm{sec}$.

(118) The use of $R(t)$ in Equation 5-41 compounds the problem of nomenclature previously mentioned. Below the equation it says that the terms were previously defined. On page 5-38, $R$ is defined as an arbitrary distance. One has to return all the way to page 5-33 to find $R$ defined as a resuspension factor.

(119) Page 5-43. If $\lambda_{w}$ were defined, it would be possible to plug prevlous numbers into Equation $5-42$ and calculate the additional exposure resulting from the resuspension factor assumed on page 5-33. For $\lambda_{w}$ appropriate for half-lives up to about a year, this leads to resuspension exposures on the order of about 10 percent of the original exposure. It is important to point out this relative importance.

(120) It should be pointed out that the population density $(p)$ is the average population density over the area $A$ and is not an independent variable. 
(121) Page 5-44, paragraph 1. Figure 5-20 is good, but it is very general. ' Equation 5-46 appears to be a specific calculation, but its results are not shown in graphs. Besldes, its derivation is not shown.

(122) It is less than obvious why to is introduced into Equation 5-46. No material can be released elther to the dissolved compartment or the sediment sink compartment until dissolution of the encapsulation. One then has a simple three compartment nonfeedback system and the equation for each individual compartment can be very simply written.

(123) Somewhat more discussion should be provided as to why an arbitrary 50 years is considered reasonable for the removal hal $f-l i f e$ associated with covering the intact fuel with sediment or encrustation, particularly when a 3-1/2 year hal $f-11$ fe is taken for dissolved fuel being incorporated in the sediment below the top $6 \mathrm{~cm}$. The relatively rapid binding of material that is in the dissolved state of the liquid phase and the relatively long avallabllity of intact fuel on the bottom of the water body need some rational explanation.

(124) Page 5-46. At the top of this page it says that Figure 5-21 presents results for a range of $\lambda_{d}$ and $t_{0}$ values. There is no indication that $t_{0}$ is considered in this graph. It would be useful to have a physical explanation for both the positions of the maxima and the meaning of the $y$-axis.

(125) Paragraph 2. Equation 5-32 (the time of flight equation on page 5-27) is mentioned as being applicable to high altitude releases over water, yet in the next paragraph it states that to is taken to be 0 . What, therefore, is Equation 5-32 used for?

(126) The question of to seems only important insofar as decay is concerned. Whether one is talking about a reactor or an isotopic system, decay can be handled completely apart from the intercompartmental transport, unless one is considering different partitioning for the fission products. However, if this is the case, then the problem becomes much more complex and cannot be handled by the simple mathematics shown.

(127) It is unclear what the area "determined using information in Section 5.1.1.1" means. Does it mean the equal area latitude bands or the area of the entire earth?

(128) Equation 5-47 is another one of those needless equations to which something called the "mean value theorem of the integral calculus" is invoked. Equation 5-48 simply states that if you take the total quantity of dissolved fuel divided by the volume of water in which it is dissolved you get an average concentration. This isn't integral calculus, it's arithmetic.

(129) Equation 5-48. These two equations cannot both be correct at the same time. $V$ is left out of the first one. 
(130) Page 5-48. The first paragraph says that "the density of sea food caught annually in coastal waters has been estimated in Reference 2," and then a value is given. Reference 2 is the OSM. Do we find this value some place other than here? If so, the volume and the page should be indicated.

(131) The last paragraph makes little sense. Are two vol umes -- one that produces an individual's annual food requirements and another that produces the annual requirement for the entire world population -being discussed? It is not clear, and in any event, how can one assign an arbitrary dilution volume to the total quantity of material released?

(132) This chapter tralls off into nothingness. There is no attempt to summarize the basic equations or the calculations. The last few paragraphs are interesting, but conclude almost nothing. This lack of a summary is a serious deficlency in much of this appendix.

(133) Page 6-1. It might be easier to write the basic equation (Equation 6-1) unsubscripted and simply note that it includes a number of pathways and a number of organs. Then, simply state that the total dose to any individual organ is summed over the various pathways that are indicated at the bottom of the page.

(134) Paragraph 1. Again, computations are contained in a computer code which probably will not be accessible to most readers. It would have been much better to show the major dose sources, rather than treat them all equally. On line 5, "calculations" is misspelled.

(135) Paragraph 3. Define "ground shine," and "air immersion."

(136) Equation 6-2. At the bottom of the page, a term is used for specific activity (SPA). This same term could have been used back on page 5-18 (in Equation 5-19). Also, there is an inconsistency in definition. Here $X$ is identified as time integrated concentration. In the past this has been used for concentration. A physical explanation for this equation is needed.

(137) Page 6-2. The $w$ in Equation 6-3 should be $\bar{w}$ Implying that it is an average value and it should be averaged over the same area that ${ }^{\circ} G_{k}+X$ is averaged. It should be made clear that the averaging is apparently done over both time and space. A clearer explanation without all the subscripts would certainly be helpful.

(138) At about the center of the page where weathering removal is indicated, it should be pointed out that the weathering removal for vegetation is not necessarlly the same as for resuspension, plant uptake, and/or ground shine.

(139) Page 6-3. This page contains a series of presumably standardized equations for dose pathways. The main problems with them are two-fold. First, there is no indication if the calculations have ever been verified, and second, the values of the coefficlents used are probably highly uncertain. No indication is given that either of these problems has been addressed. 
(140) Equation 6-5. Includes two parameters related to vegetation: (1) $Y_{V}$ identified here, and (2) an $r$ as a part of $C_{V}(t)$ identifled in Equation 5-30 on page 5-25. The ratio $r / Y_{v}$ is equivalent to the a defined on page 11 of Appendix $F$ in Volume 2. The value of $r$ is not specified in Section 5, but by comparison with the graph (page 5-41) one can approximate a value for $\alpha$. It appears to be more than one order of magnitude higher than the value used in the appendix. Why?

(141) Page 6-4. Table 6-1. This overwhelming set of data comes out of nowhere, and is not interpreted in any way. There is no indication that any of the numbers are uncertain to less than $0.1 \%$.

(142) Page 6-5, equation 6-8. There is 1 ittle or no evidence presented that this and the following equations bear a relationship to reality. Do they? A mass of equations is presented, but no effort is made to relate one to the other.

(143) At the middle of this page there is a discussion of contaminated potable water. Since for the most part, water is treated before use, and since a great deal of work has been done on the removal of fission products and other radioactive materials by normal water treatment, has this been factored into the calculations? It is not even mentioned, and whether disregarded or not, it should be discussed.

(144) Equation 6-9. Where did the assumption about 24 hours residence in water bodies come from? The same question applies to the division between $f$ ish and nonflish seafoods.

(145) Page 6-6, equation 6-10. Where did the value of seven days come from? Reference is made to Table 6-1, but since this table is not explained in the text, the reader cannot use this table easily.

(146) Paragraph 2. The term "environmental medium concentrations" is clumsy. In general, the entire paragraph is confusing. On line 5, it is stated that concentrations are stable for up to one year (without reference). On the other hand, it is stated on line 9 that equllibrium is reached instantly. There clearly are a number of concepts here which are not explained adequately.

(147) Paragraph 2 cautions that because of the assumption of biological equilibrium, inaccuracies in estimating median concentrations are introduced and that these inaccuracies are minimal when integrating concentrations over long time periods. Just what is meant here is unclear. It seems nonsense to say that the inaccuracies inherent in assuming equilibrium when equilibrium does not exist can somehow be minimized by integrating dose over long time periods. 
(148) Paragraph 3. It is stated that references are given in the table, but none are apparent. The third sentence here is completely obscure. What time periods are referred to? The fourth sentence is similar. How does one know that the data are "typical" of the world? All sorts of hidden assumptions are being made. It is probable that in the last two paragraphs on this page, Table 6-1 should be 6-2 and Table 6-2 should be $6-3$, adding to the confusion.

(149) Iable 6-3, which this paragraph presumably refers to, is not explained at all. Since it occupies a substantial portion of this section, this is a great lack.

(150) Page 6-7. Table 6-2. Supply some references. Is there absolutely no uncertainties in the data? In the previous page, it was stated that data apply to the world population. Are the data on this page of U.S. origin, or do they apply global ly? We suspect the latter, based on the low meat consumption, but the applicability should be stated.

(151) Page 6-8. Table 6-3. Some discussion of the most important parts of the lengthy table is necessary to avold readers having to plow through endless data. In the second column, what is "tau"?

(152) Page 6-16. paragraph 3. The discussion from this point on seems strangely out of place. Previous to this there was a discussion of a model. From here on the text appears to be a discussion of a user manual for a computer program which is not identified. Is this the FORTRAN code mentioned on page 6-1? Other than the statement on page $6-1$, the code is not referenced.

(153) Page 6-17. The discussion on this page is al so related to a computer program. In this case, it is referenced (Reference 42) -- is this the code mentioned on page 6-1? The reference to "Capo's parameter definitions" and "Albert-Wetton kernel" may be meaningful to some, but without references the interested reader is unable to even pursue the question.

(154) Section 6.2. The page is almost nonunderstandable, with various terms coming out of the blue. It would take far too long to comment on each. In any case, nothing has been mentioned up to now about intact fuel, so the entire discussion comes as a surprise. This section is clearly an "add-on." No account is taken of possible cleanup measures, such as occurred in Operation Morning Light.

(155) Paragraph 4. There should be an indication that this whole section is related to pl utoni um-238 fuel.

(156) As usual, there is no summary of the assumptions or conclusions, leaving the reader hanging in mid-air. This is an omission in many of these chapters, reducing their usefulness.

(157) Page 7-1. This page is a clear presentation, as is the following one. 
(158) Page 7-3, paragraph 2. In referring to Table 7-1, it would have been worthwhile to show a range of values, rather than just one. If only one is chosen, some explanation of the cholce is necessary. Otherwise, why show all the values? Also, the NCRP values are mentioned in the text, but not in the table.

(159) Paragraph 4. Section 6.2 is mentioned. This is probably a reference to Section 7.2. At the time this report was apparently prepared, the BEIR III report was new. Now it is not and should be incorporated in any revisions.

(160) Some indication should be given how the I inear-quadratic model estimates risk as compared to the linear model. Right now, the former is just words on paper.

(161) Page 7-4. Table 7-1. There is no explanation as to how column 8 ("Used in this Study") was arrived at. Is this just arbitrary, or were some specific judgments involved? Each of the decisions would seem to be meaningful, since there is no obvious common pattern in selection of the values from those presented in the rest of the table.

(162) Page 7-5, section 7.2. Until page 7.6, this is well written, clear and accurate, and one of the best in the whole OSM.

(163) Paragraph 2. It should indicate that whole body natural background radiation ranges from about 0.1 to about 0.2 rads.

(164) The reference to the uncertainties in BEIR III in the next to the last paragraph are equally true about BEIR II and other risk estimates. If this precludes strict quantitative interpretation, how does one justify Table 7-1 and other subsequent risk estimates which are used in a strict quantitative sense? It is unclear just exactly what is being implied here.

(165) Paragraph 5 seems somewhat out of place.

(166) Page 7-6. paragraph 4. The discussion here gets somewhat fuzzy, with no quantitative data to which the reader can refer.

(167) Page 7-7. By this stage, the discussion of BEIR III has gone on far too long. This page and related ones should be el iminated or pruned drastically. The section begins to read l ike an added on summary of BEIR III. It is unfortunate that the numbers in that report were not mentioned until page 7.8 .

(168) Page 7-8. This is an interesting discussion, but if the results aren't used in the calculations, why bother? Also, the values of Equations 7-2 and 7-3 are many orders of magnitude different from those in Table $7-1$, indicating that a large factor is missing. The same statements apply to Table 7-2 and Figure 7-1. In the latter table, the letters "let" should be capitalized. Also, the units are different from those in Table 7-1, making the two difficult to compare. 
(169) It is not clear that the excess risk that is being presented is on the basis of one million people being exposed. Also, it should be made clear whether this is risk per million man-rads or risk per year per million man-rads.

(170) In the next to the last paragraph on this page the reference to Equations 1 and 2 should be Equations $7-2$ and $7-3$ respectively.

(171) Page 7-9. Figure 7-1. This graph is poorly labeled. Here again excess risk should be given a clear defintion.

(172) Page 7-10. Table 7-2. It would seem reasonable to present the data in this table in the same form as that in Table 7-1 -- or present Table 7-1 in a common form with this one. More importantly, one might ask: Why present Table 7-1 at al I if the data in this table are considered more appropriate for safety analysis?

(173) Page 7-11. There seems to be little point in showing values for speciflc organs unless there is some comparison to the values prevlously assumed. There is not.

(174) Following Equation 7-4 it states these calculations are shown in Table 7-3. However, $H_{i}$ is not presented at all in Table 7-3. Also, $M_{i}$ is not defined.

(175) Equation 7-5. DT.B. should be defined as population dose in terms of millions of man-rems. Also, which of the values in Table 7.2 is $\mathrm{H}_{T}$ ?

(176) Page 7-13. In the paragraph following Equation 7-6 it states that $H_{L}$ is the leukemia and bone cancer estimator from Table 7-2. There are values for an absolute model, relative model, and average for two different terms and exposure. Thus, one has a cholce of six different values. Which one is to be used? What is the purpose of listing equations 7.6 and 7.7 if they are not to be used or compared with the equations in the previous chapter?

(177) In the last paragraph there is something missing in the sentence: "This is equivalent to saying that from 60 to 1100 disorders will occur man-rem gonadal dose." It seems odd to start discussing genetic risks here when they haven't appeared anywhere else in the document. There is little point to this.

(178) Page 8-1. paragraph 1. It should be made clear if this "update" is really incorporated in the calculations or is more of the nature of a possible update.

(179) Paragraph 3. This seems highly important, yet is somewhat unclear. When one looks at the figures (Figures 8.1 and 8.2 on the following pages) the effect of what is being sald in this paragraph is to change the calculated dose by over three orders of magnitude. Yet there is no clear indication of what has been changed. In Table 9 on page 6 of Appendix $F$ in Volume 2, the lung clearance parameters for what we assume to be INHALE $\mid \|$ are provided. Which of these parameters have been so changed as to result in the large difference lllustrated in Figures $8-1$ and $8-2$ ? 
(180) Earagraphs 2 and 3. This is far too complicated and detailed. The mysterlous 4 micron boundary is again referred to, without any indication where it came from.

(181) Page 8-2. The discussion here seems to Imply that nasopharyngeal deposition has changed. Yet at the very beginning of the last paragraph on page 8-1 it is stated that the basic lung dynamics model remains the same. If, as seems to be indicated in this discussion, INHALE 1 II restricts the fraction cleared from the nasopharyngeal region to that of the small intestine, then the case should be presented, the assumption made, the curves drawn. Is the difference between INHALE III and ICRP (and what is illustrated in the figures) a reflection of the fact that in one case the fraction cleared to the blood is assumed to be restricted to a value similar to the small intestine while in the other it is taken to be 0.001 ? If so, it should be clearly stated -- if not, it should be clarified.

(182) Page 8-3. Figure 8-1 and Page 8-4. Figure 8-2. ICRP 19 is neither mentioned in the text nor in the references. Is that something other than that which is being discussed in the text?

(183) Page 8-4. The entire appendix comes to an inconclusive ending, without any attempt to explain what the mass of text, data, and graphs means. As well, what differences there are between this work and Vol. 2 are unclear.

(184) Page 9-1. As noted in Volume 2, the references are often unsatisfactory. An example of a falrly good one is no. 10, where the report number, publisher, and place of publication are listed. However, almost all the reports have no speclfic page numbers I isted, Implying the reader has the time and patience to go through perhaps hundreds of pages to find one plece of data.

A few examples of inadequate references are no. 98, no publisher, place of publication; no. 24, no title; no. 6 , no publisher, place of publication; no. 19, no author, place of publication; no. 20, same as no. 19. This list could be extended greatly. In ref. 47, reference is made in the text to four reports which are reviewed in it, but one could not guess this from this reference.

Finally, reference 2 is the OSM itself. Self-reference is not allowed. This suggests that Volume 4 was an afterthought to the main OSM.

(185) Appendix B. In the Table of Contents, appendices to this appendix are listed, which is confusing. In any case, the page numbers for these appendices should be listed.

(186) While the intent of this appendix is good, little evidence is supplied that the array of equations and data in this and other volumes is included in it. Unless that evidence is supplled, the code shown will prove lit+le. 
(187) Appendix 2. It is stated here that a sample problem is solved, but no evidence of results, parameters, etc., is shown. The computer printout is only partly legible, so the final data are hard to read.

(188) The intent of Appendix B, to show the computer code used and sample calculations, is good. However, the work is very difficult to follow, with little or no explanation, semilegible printouts, etc. It would have been far better to go through all the relevant equations, step-by-step, to show how a final result was achleved. This could occupy much of Vol. 4 which, as noted above, is far from helpful in its present state.

(189) Although an Appendix 3 is promised in the Table of Contents, it is nowhere to be found. Both appendices shown have no page numbers, which makes using them more difficult.

(190) Appendix $\mathrm{C}$. This appendix is almost completely useless. The authors have gone to great trouble to complle the bibliography, and there is little doubt that it was fairly complete on the date shown. However, the authors have made no attempt to tell readers what these hundreds of papers mean. When plutonium is mentioned el sewhere in the text, it is only briefly and with no indication that there may be variability in the data. This appendix is clearly of an "add-on" nature. If it were transformed into an annotated bibliography, with a discussion of the data and its variability, it could be quite useful. At the moment, it is not.

(191) Appendix D. Readers cannot tell if the proposed work was ever carried out, or what its results were. In any case, there is no evidence shown that the work would significantly improve the accuracy of the overall results, given the uncertainties in other areas.

(192) Page 1. paragraph 1 and 2. This is a repeat of other sections.

(193) Page 2, paragraph 3. Exactly what was wrong with the grid that was formerly used?

(194) Paragraph 5. What is "cultural" data? How does it fit in?

(195) Paragraph 5. Avold the use of appendices to appendices -- this is confusing.

(196) Page 4. paragraph 5. Again the word "cultural" comes up without any explanation of its meaning.

(197) Page 6, paragraph 1. How does the present work differ from the rest of the OSM? This is unclear.

(198) Page 7. This figure is illegible.

(199) Page 11. paragraph 2. Une 6. Use "purposes." In the next paragraph, the reason for describing the project is obscure. 
(200) Page 12, paragraph 3. What is "footprint and debris hazard"?

(201) Page 13. Elgure 3. What do the values in the table mean?

(202) Page 16, paragraph 2. This information is out of date by now.

(203) Page 18, paragraph 2. Very few people are involved, so the point of the paragraph is unclear. The meaning of paragraph 4 is not given.

(204) Page 22. Elgure 6. This is just a repeat of Table 2.

(205) Page 24. paragraph 2. Explain "dladromous."

(206) Page 33, paragraph 3. What relationship does this have to risk?

(207) Page 35. Figure 2. Can this large figure be reduced?

(208) Page 40. No results of any of the above are shown.

(209) Page A-1. These could be useful recommendations, but it is unclear if they have been adopted. 